(c) 2020 Elsevier. This manuscript version is made available under the CC-BY-NC-ND 4.0 license http://creativecommons.org/licenses/by-nc-nd/4.0/

https://doi.org/10.1016/j.engfracmech.2019.106761

\title{
Assessment of CNT-doping and hot-wet storage aging effects on Mode I, II and I/II interlaminar fracture toughness of a UD Graphite/Epoxy material system
}

Theofanis S. Plagianakos ${ }^{* 1}$, Kirsa Muñoz ${ }^{2}$, Gerard Guillamet ${ }^{3}$, Vasileios Prentzias ${ }^{1}$, Adrià Quintanas-Corominas ${ }^{4}$, Miguel Jimenez ${ }^{2}$ and Evangelos Karachalios ${ }^{1}$

1. Hellenic Aerospace Industry S.A., P.O. Box 23, GR 32009, Schimatari, Greece

2. Element Materials Technology Seville, San José de la Rinconada 41300, Seville, Spain

3. Barcelona Supercomputing Center (BSC), Jordi Girona, 29, 08034, Barcelona, Spain

4. AMADE, Polytechnic School, Universitat de Girona, Campus Montilivi, s/n, 17071 Girona, Spain

\footnotetext{
“Corresponding author plagianakos.theofanis@haicorp.com
} 


\begin{abstract}
The interlaminar fracture toughness of two unidirectional Graphite/Epoxy composite material systems has been experimentally assessed. The systems studied were prepreg composite and prepreg composite treated with carbon nanotubes (CNT). The fracture toughness has been quantified in Mode I, Mode II and Mode I/II by performing $\mathrm{DCB}, \mathrm{ENF}$ and MMB tests according to relevant ISO and ASTM standards. The effect of aging by storage under hot-wet conditions has been quantified by studying these systems at room temperature without aging and at $70^{\circ} \mathrm{C}$ after aging treatment. Experimental data are reported in a 3- or 5-specimen batch mode, indicating non-linear behavior and sensitivity to imperfections in coupons alignment and load application. Moreover, intermediate variables required for the estimation of fracture toughness are presented in order to be used as a reference guide for principal fracture test data evaluation. In the case of the RT systems, measured data have been compared with analytical solutions and finite element model predictions yielding good correlation for $\mathrm{DCB}$ and ENF tests and considerable deviation in the case of MMB tests. Main findings include that CNT-doping leads to an increase of fracture toughness in all modes, especially in Mode II, and that aging leads to less variation in measurements for both systems, indicating a more uniform matrix response.
\end{abstract}

\title{
Keywords
}

composites; fracture toughness testing; CNT; aging 


\section{Introduction}

Composites have been established as most successful material candidates in the major part of commercial and military flying items, while their use is expected to grow further in the near future [1]. Their interlaminar fracture toughness (ILFT) is one of the critical material parameters taken into account in analytical and numerical models during conceptual design phase, manufacturing and operation, while this may be improved by incorporation of carbon nanotubes (CNT) to the composite material system [2-3]. In both "control" and CNT-doped laminations, its experimental assessment is essential in order to ensure quality dictated by industrial standards in the context of material characterization. Moreover, quantification of the effect of hygrothermal aging is very useful at the design stage for predicting material degradation in terms of ILFT during operation. In most cases it is required that ILFT tests are conducted in batch mode, as to provide a statistical overview of fracture parameters in terms of mean value and variance.

As far as experimental verification of ILFT of composite materials is concerned, pioneering works [4-12] led to the development of ISO [13] and ASTM [14-16] standards for Mode I, II and I/II, which are widely used for measuring fracture properties with common reference. These research works have been extensively reviewed, among others, by Tay [17]. In parallel, simulation tools and/or damage criteria have been proposed and established for predicting interlaminar fracture initiation and propagation in composite materials, among others by Camanho, Davila and de Moura [18], Chrysochoidis and Saravanos [19], Sorensen and Jacobsen [20], Naghipour et al. [21], Turon et al. [22-23] and Goutianos and Sorensen [24], while relevant literature reviews have been conducted by Orifici, Herszberg and Thomson [25] and Mishnaevski and Brondsted [26]. The field of fracture modelling in composites has been continuously attracting attention up to date, as indicated by numerous book [27-28] and journal publications [29-30].

In the field of research on enhancing fracture toughness of long fiber composites with CNT early works were mainly experimental [31-33], while numerical multi-scaled modeling methods have been also formulated for predicting the properties of the multifunctional composite at the ply level [34-36]. Thakre et al. [37] experimentally studied the effect of spraying single wall CNT to the midplane of woven carbon fiberepoxy laminates on their Mode I ILFT, while Wicks et al. [38] focused on CNT grown on the surface of woven fibers. Falzon et al. [39] applied CNT agglomerations on a substrate transferred to pre-cured laminate interfaces and achieved $31 \%$ and $61 \%$ increase in $G_{l c}$ and $G_{\| c}$, respectively. Ayatollahi, Shadlou and Shokrieh [40] and Silva et al. [41] experimentally determined the effect of multi-walled CNT incorporation on the mixed mode I/II fracture toughness of epoxy matrix and glass/epoxy composite, respectively. Kumar and Roy [42] characterized the interlaminar fracture behavior of nanographene reinforced epoxy and its carbon fiber composite in mixed mode and Mode I, respectively. Abidin et al. [43] manipulated the matrix microstructure to promote controlled Mode I crack propagation in regionally enhanced CNT reinforced carbon fiber epoxy composites. Dikshit, Bhudolia and Joshi [44] conducted an extended review on interlaminar fracture improvement of CNT reinforced composites and focused on related manufacturing processes. Rodriguez-Gonzalez and RubioGonzalez [45-46] experimentally determined the ILFT enhancement achieved in carbon fiber/epoxy prepreg laminates sprayed with multi-walled CNT. Khan, Bedi and Agnihotri [47] measured Mode II fracture toughness of carbon fiber/epoxy and reported a 53\% increase by application of CNT grafting. Ravindran et al. [48] applied multi-scale 
carbon-based reinforcements and studied the Mode II ILFT both experimentally and numerically.

As far as the effect of hygrothermal aging on the fracture toughness of composites is concerned, early works in the 80's and 90's [49-55] were experimental, whereas Chamis [56] developed design tools based on micromechanics for encompassing hygrothermal effects. The main conclusions of these works were that Mode I fracture toughness yields a slight change due to aging, whereas it gets drastically decreased in Mode II. Davidson, Kumar and Sofa [57] conducted DCB, single leg bending (SLB) and ENF tests on thermoplastic carbon/epoxy composite specimens and quantified the effect of aging conditions and fracture mode ratio on ILFT. Alessi, Pitarresi and Spadaro [58] studied the effects of ageing on Mode I ILFT of carbon/epoxy composite specimens. Fard et al. [59] experimentally determined the critical energy release rate initiation and resistance curves for stitch-bonded nanocomposites and developed mode I/II failure loci incorporating effects of temperature and humidity. Recently, Rodriguez-Gonzalez et al. [60] reported DCB and ENF tests on seawater-aged carbon/epoxy composite specimens containing carbon nanofillers, whereas Fard et al. [61] studied the effects of extreme environmental conditions on Mode I, II and I/II in polymer-matrix composites and developed an envelope function for the mixed-mode to be used as a design guideline in aerospace and nuclear industry.

Thus, it seems that limited work has been done towards determination of ILFT in hygrothermally aged composite systems reinforced with CNT. Moreover, experimental data for ILFT in open literature are provided as measurements on single-specimen tests, while a batch-mode approach would highlight the non-linear nature of these tests and provide values for variance and/or standard deviation.

The present work primarily aims at systematically quantifying the effect of hygrothermal aging by storage under hot-wet conditions on ILFT of a carbon fiber/epoxy prepreg composite material, in a pure (control laminate) and a CNT reinforced configuration. In this context, experimental data of ILFT in Mode I, II and I/II tests are reported in batch mode for non-aged and aged composite systems. Thus, wherever appropriate, measured values are provided by means of a mean value and a coefficient of variance, highlighting deviations attributed to test procedural non-uniformities. Moreover, in order to guide researchers along the methods dictated from the standards [13-16] for evaluating fracture toughness in composite material systems, all quantities required for estimating fracture toughness according to relevant standards are reported herein for each specimen. Regarding fracture modeling, in the case of nonaged material systems the measured data have been compared against analytical solutions [22] and non-linear numerical models developed in commercial and in-house finite element software, MSC MARC [62] and Alya [63], respectively. Those predictions have been based on linear elastic material properties determined at the composite ply level. As a brief paper summary, after a short report on specimen manufacturing and aging process, fracture tests configurations and methods are described and analytical solutions are provided accompanied by a short description of the finite element (FE) models. The major part of the paper includes reporting and commenting of experimental and numerical results. Finally, main conclusions are provided focusing on the effect of CNT-doping and aging on the ILFT of a carbon-epoxy composite material system. 


\section{Specimen Fabrication}

The material used to fabricate the specimen was thermoset prepreg M21/T800S by Hexcel. The same prepreg material was further processed by ADAMANT in order to produce the second material variant with integrated CNTs at prepreg/“lamina" level.

\subsection{Control prepreg}

Plates were manufactured following manual hand lay-up (HLU) process and were then cured following typical autoclave manufacturing process. The plies were stacked on a metallic mold with necessary flatness for coupons fabrication. For every 4 composite plies laid on the mold a debulking step was performed in order to achieve appropriate compaction and degas the laminate from any possible air bubbles enclosed during the lay-up process. A layer of release film A6000 ETFE $0.012 \mathrm{~mm}$, by AEROVAC, was inserted during the layup at appropriate position in the middle of the layup in order to create the initial debonded length required by the fracture standards [13-16]. A dedicated caul plate was installed onto each composite plate in order to achieve a uniform thickness. The caul plate was made from Al alloy and had a thickness of 0.192" $(\approx 5 \mathrm{~mm})$.

\subsection{CNT treated prepreg}

Adamant Composites Ltd in collaboration with the University of Patras developed a processing technology, commercially termed FXply ${ }^{\mathrm{TM}}$ prepreg technology, and a PILOT line for scaling up the production of CNT treated prepregs. The process is an industrial Roll-to-Roll process and the integration of the CNT takes place in-line with consecutive processing stations. Thus, the product form remains the same; a prepreg roll, and the rest of the CFRP production process (e.g. cutting, kitting, layup, curing) does not change. The FXply ${ }^{\mathrm{TM}}$ prepreg used in the present work was treated with $1 \% \mathrm{wt}$ of NC7000 MWCNT from Nanocyl, Belgium and corresponds to a final MWCNT loading of $1.0 \% \mathrm{wt}$ of the resin of the uncured prepreg. The treatment process is an industrial process delivering a homogeneous distribution of the MWCNT contained in a polymer encapsulant, on the surface of the prepreg. A typical SEM image of a MWCNT treated prepreg (not from the one tested) is shown in Figure 1.

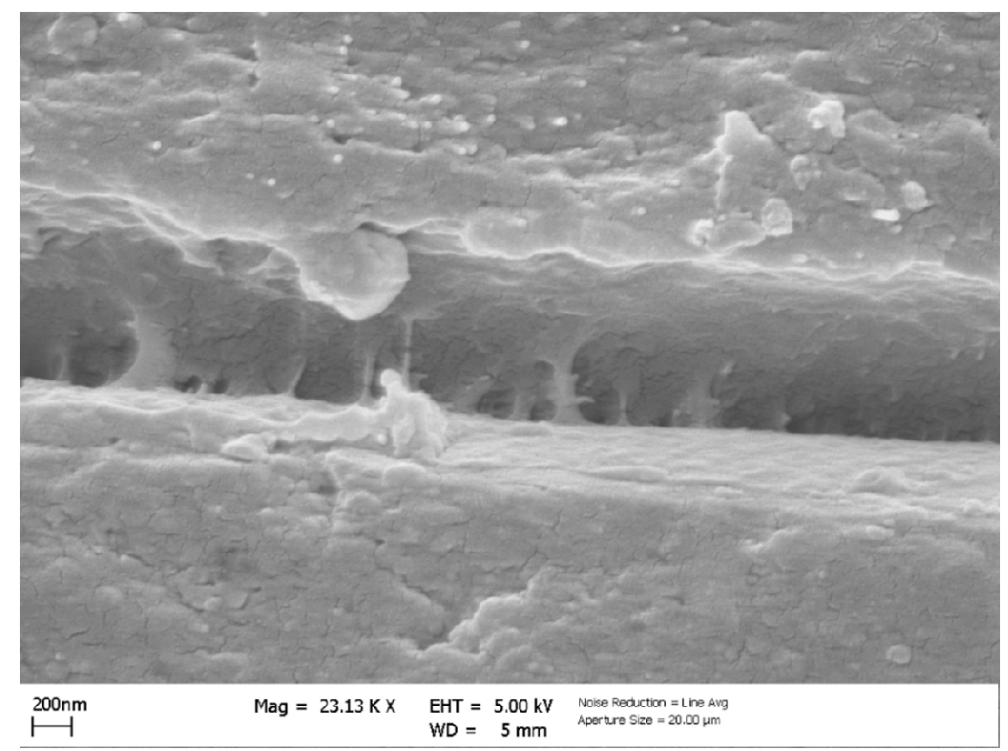

Figure 1: Typical SEM image of MWCNT-treated prepreg (from Adamant Composites Ltd) 


\section{Specimen Aging}

During its service life, an aircraft is exposed to high temperatures and high levels of humidity. Properties of composite materials may be affected as a consequence of moisture absorption and high temperature. A faithful replication of the environmental exposure during aircraft operation would require a cyclic conditioning procedure between hot/humid and cold/dry conditions as dictated by relevant standards (MILSTD-810 or other). In the proposed work we have followed an accelerated conditioning procedure on the basis of common practice [64], which would be a small part of an extended experimental aging campaign towards material airworthiness certification.

In order to evaluate the degradation of their mechanical properties, an environmentally conditioned testing scenario was considered according to ASTM D5229/D5229M [65]. The selected method is a recommended pre-test conditioning method in [65], consistent with the recommendations of Composite Materials Handbook-17 [66]. Specifically, the procedure that has been followed in these test series is a conditioning procedure BHEP [65], which covers non-ambient moisture conditioning of material coupons in a humidity chamber at a prescribed constant conditioning environment to equilibrium, periodic coupon weighing being required. Two different types of test series were covered. On the one hand, room temperature (RT) tests were conducted on specimens without any conditioning. On the other hand, parallel test series were performed on specimens that have been previously conditioned. These are known as Hot Wet (HW) tests.

The conditioning parameters are usually fixed according to the conditions to which aircraft structure may be subjected during its service life. This commonly means an equilibrium moisture weight in an $85 \%$ relative humidity environment and a temperature of $70^{\circ} \mathrm{C}$. Nevertheless, in order to achieve a lower completion time for the testing campaign, especially for thermoset materials which involve long environmental conditioning times, accelerated conditioning was carried out. In order to achieve faster aging process, conditioning was performed at higher temperature $\left(80 \pm 3^{\circ} \mathrm{C}\right)$, under the same relative humidity $(85 \pm 5 \%)$. It was checked that glass transition temperatures for tested materials, as provided by the manufacturers, was significantly higher than the accelerated conditioning temperature $\left(203^{\circ} \mathrm{C}\right.$ and $204^{\circ} \mathrm{C}$, respectively, for control and CNT-treated material system). By proceeding this way, a decrease of conditioning periods was achieved, speeding the rate of testing.

\section{Experimental Approach}

The experimental methodology followed includes a basic phase, where fundamental tests have been performed for determining linear elastic material properties at the composite ply level. Next, ILFT static tests have been conducted hierarchically: Mode I (Double Cantilever Beam - DCB), Mode II (End-Notch Flexure - ENF) and Mode I/II (Mixed-Mode Bending - MMB). All tests have been performed in batch-mode in order to check fabrication and measurements repeatability. For the sake of clarity the control material is defined as M1 and the CNT-doped material as M4.

All tests of the non-aged composite system (RT) have been conducted on an INSTRON 8801 hydraulic testing machine at room temperature $\left(T=25{ }^{\circ} \mathrm{C}, 45 \%\right.$ humidity), equipped by an Omega load cell with range up to $5 \mathrm{kN}$. HW tests have been performed on a Zwick Retroline (INSTRON 5866) Universal Testing Machine, equipped with an INSTRON load cell having a range up to $10 \mathrm{kN}$. The HW tests have 
been conducted under controlled temperature $\left(70^{\circ} \mathrm{C}\right)$ using thermocouples inside a temperature chamber (Thermcraft).

In the case of RT DCB and MMB tests, a Philips SPC2050NC digital camera and Debut v4.08 by NCH software (non-commercial use edition) have been used to record crack propagation, whereas in the respective HW tests and all ENF tests crack propagation has been visually monitored. The camera-to-specimen distance was ca. $130 \mathrm{~mm}$ and focus has automatically been applied at a $640 \times 80$ pixels resolution and a rate of 30 frames per second.

\subsection{Conditioning}

Conditioning process has been carried out in a climatic chamber (DYCOMETAL) at 80 ${ }^{\circ} \mathrm{C}$, under $85 \%$ R.H. The control of humidity absorption in the test specimens has been carried out using three witness specimens (known as travellers) with same thickness and material as the test specimens, and dimensions of $25 \times 25 \mathrm{~mm}$. According to [65] effective moisture equilibrium is achieved when the average moisture content of the traveller specimen changes by less than $0.020 \%$ over each of two consecutive reference time period spans. The reference time period span was set as 7 days according to [65]. The default conditioning environment set by the standard is $70^{\circ} \mathrm{C}$, $85 \% \mathrm{RH}$. A trial was performed to compare accelerated conditioning at $80^{\circ} \mathrm{C}$ against $70^{\circ} \mathrm{C}$ ageing for the control prepreg. In this trial (22 plies, UD laminate, $0^{\circ}$ ), it has been observed that the time required to achieve the moisture equilibrium was 119 days for $70^{\circ} \mathrm{C}$, while 126 days for $80^{\circ} \mathrm{C}$ conditioning. The complete moisture content curve is shown in Figure 2, where $\mathrm{x}$-axis represents the square root of conditioning days spent.

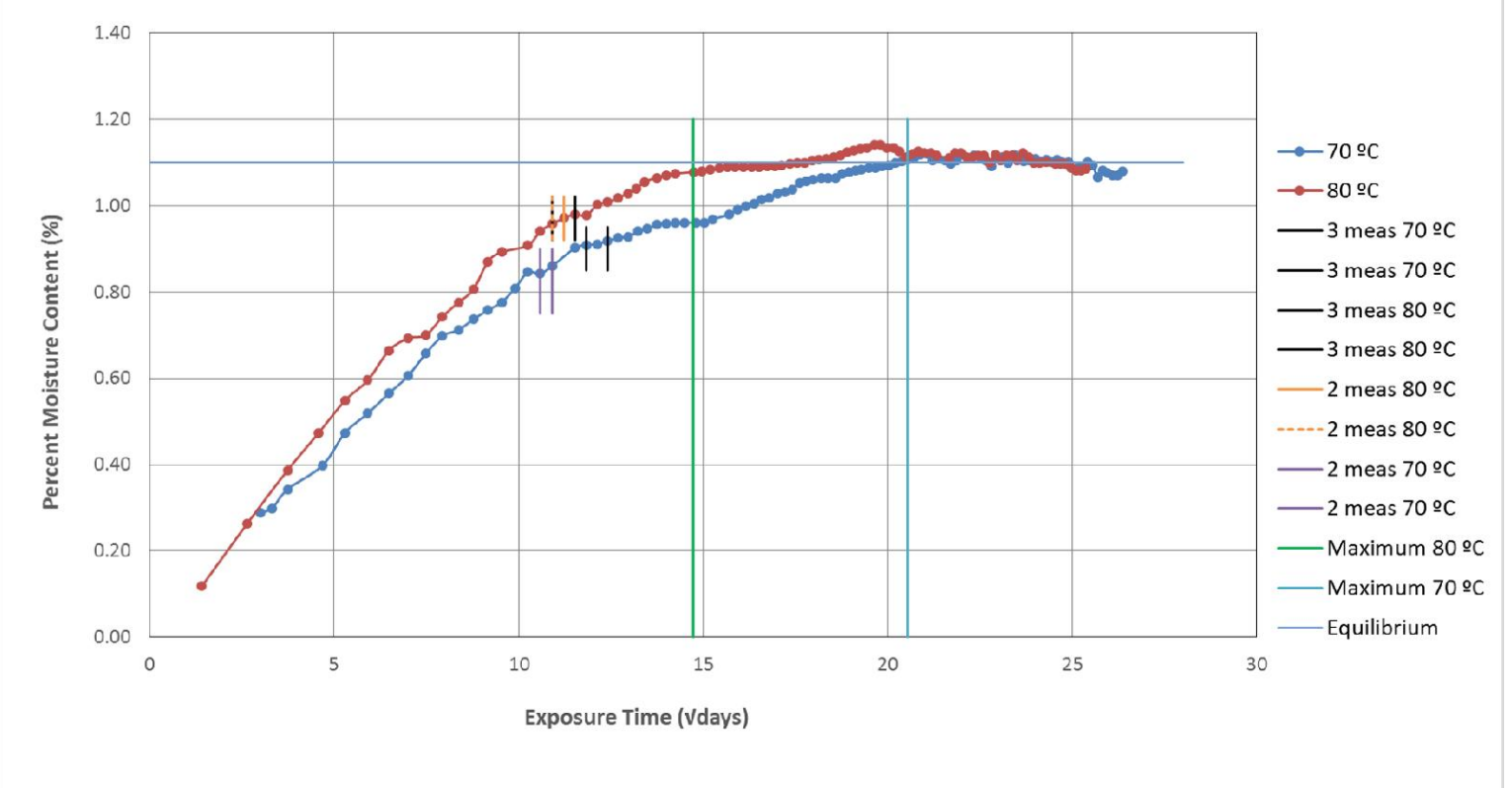

Figure 2: Moisture absorption curve for the control material system

On the basis of the moisture curve the following observations may be deduced: i) If the criterion was modified such as equilibrium is defined as three consecutive measurements where average moisture content of the material changes by less than $0.020 \%$ (black lines in Figure 2), conditioning times for $70^{\circ} \mathrm{C}$ and $80^{\circ} \mathrm{C}$ aging would be 154 and 133 days, respectively. Thus, if this criterion was followed, accelerated aging at $80^{\circ} \mathrm{C}$ would imply an increase in aging rate of $14 \%$; ii) If the two curves were compared on the basis of maximum value of moisture content equilibrium at $70^{\circ} \mathrm{C}$, 
aging at $70^{\circ} \mathrm{C}$ and $80^{\circ} \mathrm{C}$ would require 422 days and 217 days, respectively, indicating an accelerating factor of 2 for a $10^{\circ} \mathrm{C}$ temperature increase.

The tests at $70^{\circ} \mathrm{C}$ were executed without humidity control. The specimens of each test series were taken out of the HW-chamber to the test chamber just before performing the mechanical test. They were stored in a thermo-sealed bag until the specimen was placed inside the test chamber. Each specimen was mounted in the test rig inside the test chamber under controlled temperature conditions and its temperature was monitored using a thermocouple. Once the testing temperature of the specimen has been reached, it has been maintained for three minutes. Then, the mechanical test was performed.

\subsection{Material Characterization at Ply Level}

Fundamental static tests included tension [67], compression [68-69], in-plane shear [70], interlaminar shear strength [71] and flexure [72] for the control material, whereas for the CNT-doped composite indicative tests have been performed. The material properties extracted from the tests have been used as input for the analytical solutions and the finite element models developed in the context of the present work.

It should be noted that compressive properties of $0^{\circ}$-unidirectional laminate were assessed through different standards. On the one hand, compressive modulus was obtained following ASTM D695 [68] standard. On the other hand, compressive strength was assessed using EN2850-B [69] end-tabbed specimens.

\subsection{DCB-Test Configuration and Method}

The DCB tests have been performed according to ISO 15024 standard [13]. The DCB experimental configurations for RT and HW tests are shown in Figure 3. As far as the coupon geometry is concerned (Figure $3(\mathrm{a})$ ), respective dimensions are provided as $b=20 \mathrm{~mm}, 2 h=3.2 \mathrm{~mm}, l=125 \mathrm{~mm}, A=60 \mathrm{~mm}, a_{0}=53 \mathrm{~mm}, H=14 \mathrm{~mm}, l_{1}=8.5 \mathrm{~mm}, l_{2}=7$ $\mathrm{mm}$. As illustrated in Figure 3(b), the loading blocks are connected to the testing machine heads by means of pins and $Y$-shape adaptors, as to allow for free rotation of the blocks. Crack propagation has been monitored by a digital webcam and recorded using appropriate software, simultaneously to load and displacement measurements. Loading has been applied in two stages [13]: initial loading, where the initial crack propagated $3-5 \mathrm{~mm}$, and reloading up to a crack propagation of at least 50 $\mathrm{mm}$. The loading rate in both phases was $1 \mathrm{~mm} / \mathrm{min}$. The Mode I interlaminar fracture toughness has been evaluated by using the Corrected Beam Theory (CBT) method for the reloading phase.

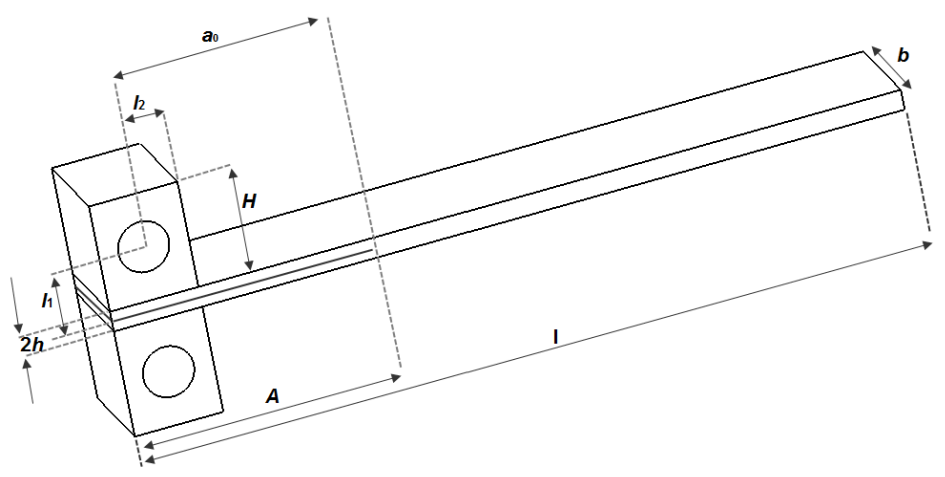

(a) 


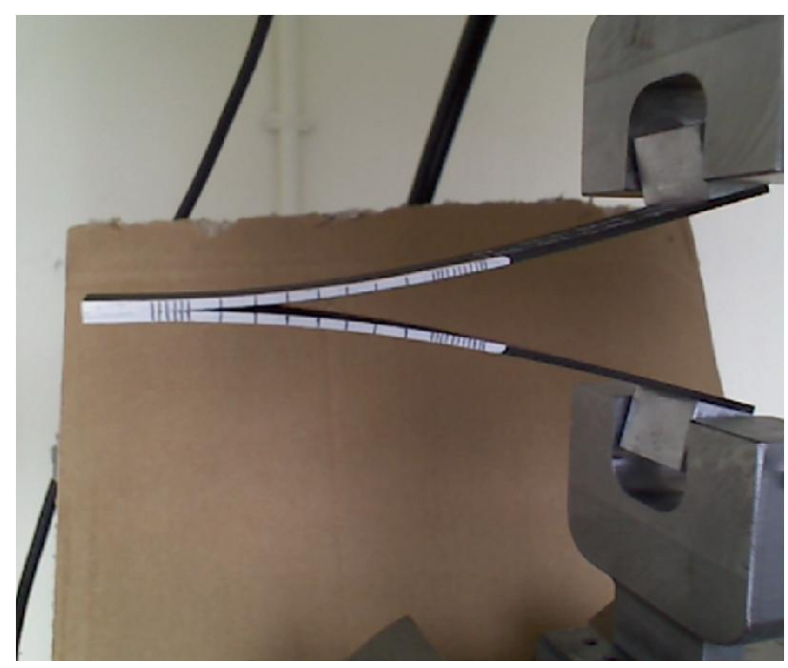

(b)

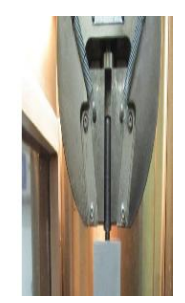

(c)

Figure 3: DCB configuration: (a) Schematic representation of DCB-coupon [13], (b) RT Experimental setup, (c) HW Experimental Setup.

\subsection{ENF-Test Configuration and Method}

The ENF tests have been performed according to ASTM D7905 standard [15] in two stages: Non Pre-Cracked (NPC) and Pre-Cracked (PC) test. The ENF experimental configurations for RT and HW tests are shown in Figure 4. Respective dimensions are provided as $2 h=4.2 \mathrm{~mm}, 2 L=100 \mathrm{~mm}, r_{1}=6 \mathrm{~mm}, r_{2}=5 \mathrm{~mm}$, insert length $a_{i}=45 \mathrm{~mm}$, distance NPC compliance calibration points from crack tip mark $a_{1}=20 \mathrm{~mm}$ and $a_{2}=40$ $\mathrm{mm}$, distance fracture test point from crack tip mark $a_{3}=30 \mathrm{~mm}$, whereas the specimen width was $b=25 \mathrm{~mm}$. Crack propagation has been visually monitored and the final delamination length has been reported. The loading rate in both phases was 0.5 $\mathrm{mm} / \mathrm{min}$. An equal unloading rate has been applied in NPC fracture test for determining the respective compliance. 


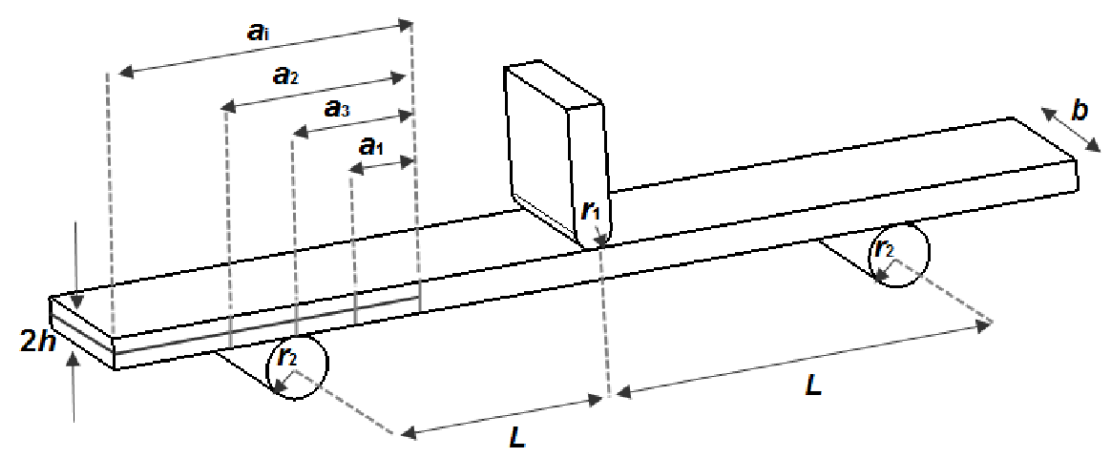

(a)

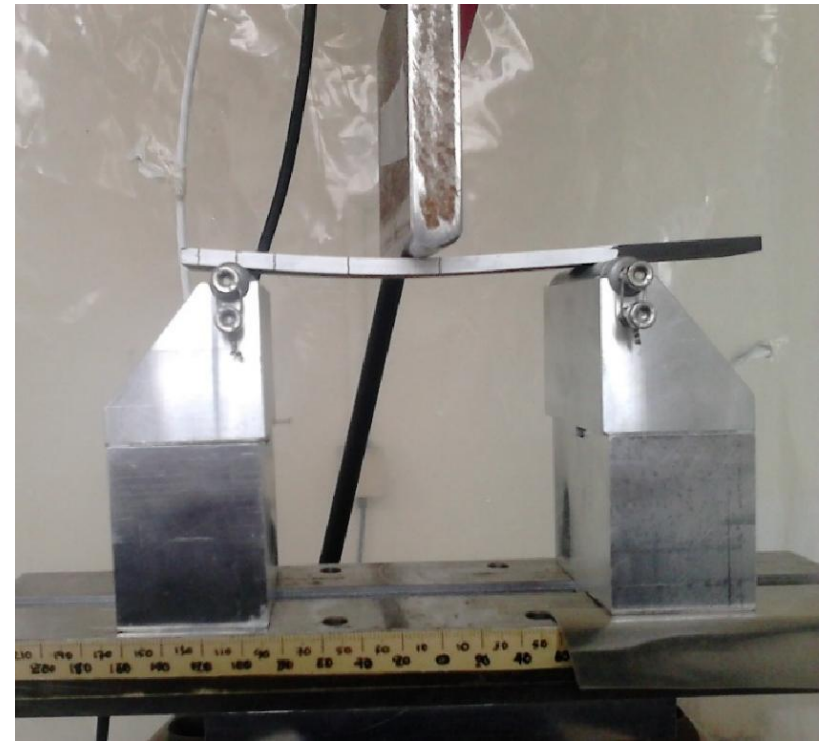

(b)

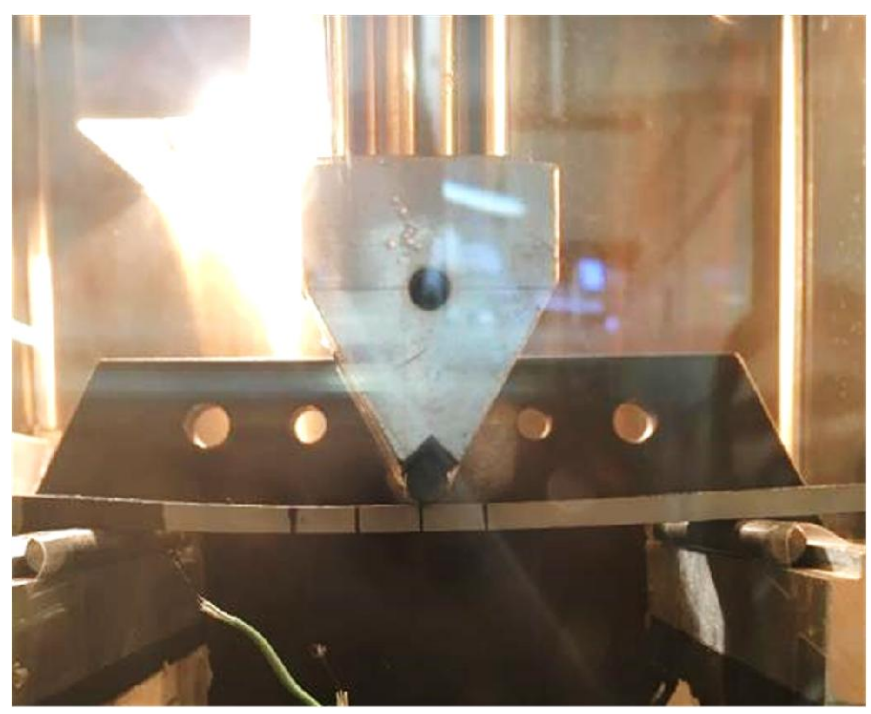

(c)

Figure 4: ENF configuration: (a) Schematic representation of ENF-coupon [15], (b) RT Experimental setup, (b) HW Experimental set-up 


\subsection{MMB-Test Configuration and Method}

The MMB tests have been performed according to ASTM D6671 standard [16]. A mode mixture of $G_{\|} /\left(G_{1}+G_{\|}\right)=0.2$ has been selected. The MMB experimental configuration is shown in Figure 5. Respective dimensions are provided as $b=25 \mathrm{~mm}, 2 h=4.2 \mathrm{~mm}$, $2 L=100 \mathrm{~mm}, a=30 \mathrm{~mm}$ and $c=93 \mathrm{~mm}$ ( $c$ being the lever length of the test apparatus), whereas the insert length was $45 \mathrm{~mm}$. Crack propagation has been monitored by a digital webcam and recorded using appropriate software simultaneously to load and displacement measurements. The loading rate was $0.5 \mathrm{~mm} / \mathrm{min}$.

At HW tests, difficulties related to the attachment of the hinges to the specimen were faced, since the shear resistance of structural adhesives significantly decreases at high temperatures. Several trials with different structural adhesives, initial delamination lengths and mode mixture were carried out to avoid debonding of the hinges. Finally, the proposed solution focused on improvement of the bonding area between the specimen and the hinge by means of an aluminum intermediate plate, which provides a perfectly plane surface to be attached to the specimen. This solution enabled to perform HW tests with a configuration which is most similar to RT tests, in terms of mode mixture $\left(G_{\|} / G_{C}=0.2\right)$ and initial delamination length $\left(a_{0}=30 \mathrm{~mm}\right)$.

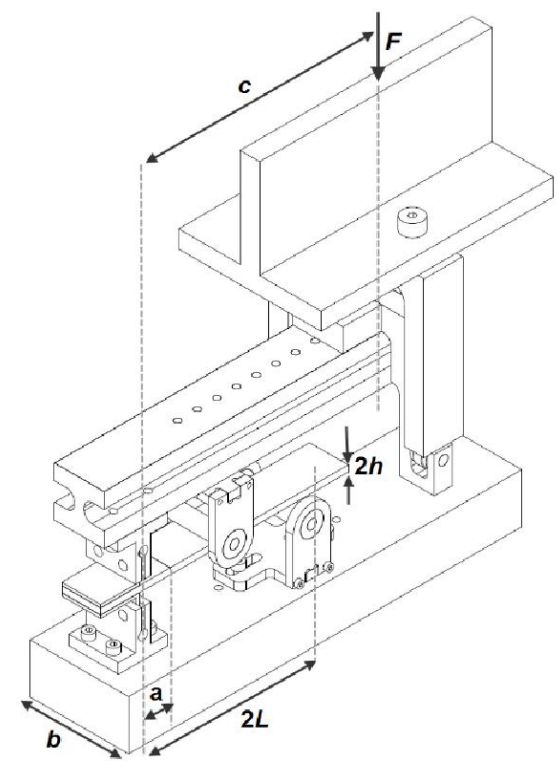

(a)

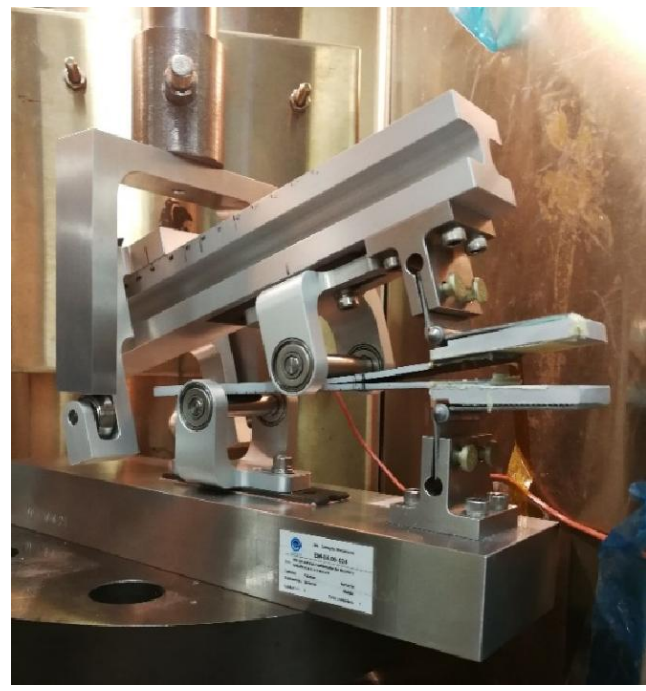


(b)

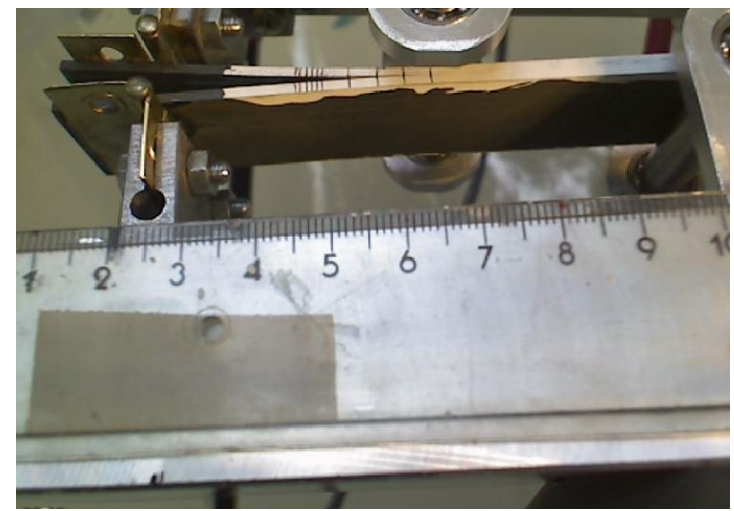

(c)

Figure 5: MMB-test configuration: (a) Schematic representation and (b) HW test set-up, (c) snapshot of RT specimen with crack during loading.

\section{Analytical Solutions}

The equations presented herein correspond to the analytical solutions for each fracture mode, which are based on Linear Elastic Fracture Mechanics (LEFM). In the present study, a correction crack length factor is used for all tests according to [5].

\subsection{Mode I}

On the basis of Linear Fracture Mechanics and the Modified Beam Theory $[5,14]$ the applied load in a DCB test is given by

$$
F_{D C B}=\sqrt{\frac{E_{11} b^{2} h^{3} G_{I C}}{12(a+\chi h)^{2}}}
$$

where $E_{11}$ is the longitudinal elastic modulus, $b$ and $h$ are width and half-thickness of the specimen, $G_{\mathrm{lc}}$ corresponds to the material fracture toughness in Mode I and $a$ is the crack length (Figure 3(a)). The correction factor $X$ is defined as,

$$
\chi=\sqrt{\frac{E_{11}}{11 G_{13}}} \sqrt{3-2\left(\frac{\Gamma}{1+\Gamma}\right)^{2}}
$$

where $\Gamma$ is the transverse modulus correction parameter:

$$
\Gamma=1.18 \frac{\sqrt{E_{11} E_{22}}}{G_{13}}
$$

In eq. (3) $E_{22}$ and $G_{13}$ are in-plane transverse and interlaminar shear moduli, respectively. The opening displacement is derived from the applied load as:

$$
u_{D C B}=\frac{8(a+\chi h)^{3}}{E_{11} b h^{3}} F_{D C B}
$$




\subsection{Mode II}

The applied load for crack propagation in the ENF test, see Figure 4(a), is calculated from geometrical, material and fracture parameters [5-6],

$$
F_{E N F}=\sqrt{\frac{16 E_{11} b^{2} h^{3} G_{\| l c}}{9(a+0.42 \chi h)^{2}}}
$$

where $G_{\| c}$ is Mode II fracture toughness. The midpoint displacement is derived from the applied load as,

$$
u_{E N F}=\frac{3(a+0.42 \chi h)^{3}+2 L^{3}}{8 E_{11} b h^{3}} F_{E N F}
$$

\subsection{Mode I/II}

The equations for the mixed-mode bending test are based on ASTM Standard [16] and they are summarized in the following. These equations include an exact solution for the determination of the mode mixture [73]. The displacement of the lever can be written as,

$$
u_{M M B}=\frac{4(3 c-L)^{2}(a+\chi h)^{3}+(c+L)^{2}\left[3(a+0.42 \chi h)^{3}+2 L^{3}\right]}{8 b E_{11} L^{2} h^{3}} F_{M M B}
$$

where geometrical parameters $b, L, h$ and $c$ and the crack length a are illustrated in Figure 5(a) and $c$ is the applied lever length derived as

$$
c=\frac{12 \beta^{2}+3 \alpha+8 \beta \sqrt{3 \alpha}}{36 \beta^{2}-3 \alpha} L
$$

with mode-mixture non-dimensional parameters $\alpha$ and $\beta$,

$$
\begin{gathered}
\alpha=\frac{1-\frac{G_{\|}}{G}}{\frac{G_{\|}}{G}}=\frac{G_{I}}{G_{\|}} \\
\beta=\frac{a+\chi h}{a+0.42 \chi h}
\end{gathered}
$$

The critical load for crack propagation $\mathrm{F}_{\mathrm{MMB}}$ appearing in eq. $(7)$ is related to the mixedmode fracture toughness as:

$$
F_{M M B}=\sqrt{\frac{\frac{4}{3} G_{c} E_{11} b^{2} L^{2} h^{3}}{(3 c-L)^{2}(a+\chi h)^{2}+\frac{3}{4}(c+L)^{2}(a+0.42 \chi h)^{2}}}
$$

\section{Finite Element Models}

The numerical simulations have been performed using two types of finite element (FE) software, Alya [63] and MSC MARC [61]. The latter, along with the analytical solution, serves as validation of the former in the pure fracture modes I and II. The numerical 
analysis complements the experimental results and provides a reliability measure of current cohesive element formulations on the prediction of delamination in the case of CNT doped materials. The material is modeled as linear elastic using material properties at ply level extracted from mechanical tests (Table 2). The interface material properties used for the FE simulations are summarized in Table 1,

\begin{tabular}{|c|c|c|c|c|c|}
\hline Material & $T_{1}(\mathrm{MPa})$ & $T_{\|}(\mathrm{MPa})$ & $G_{\text {Ic }}\left(\mathrm{kJ} / \mathrm{m}^{2}\right)$ & $G_{\| \mathrm{lc}}\left(\mathrm{kJ} / \mathrm{m}^{2}\right)$ & $K_{\mathrm{p}}\left(\mathrm{N} / \mathrm{mm}^{3}\right)$ \\
\hline M1 & 24.92 & 93.7 & 0.308 & 0.828 & $10^{5}$ \\
\hline M4 & 24.92 & 94.3 & 0.971 & 1.73 & $10^{5}$ \\
\hline
\end{tabular}

Table 1: Interface properties for the FE models

where $T_{\|}$is the shear traction (ILSS strength in Table 2); $G_{\| c}$ and $G_{\| c}$ are the critical energy release rates in Mode I and Mode II, respectively, experimentally determined in the current study; and $K_{\mathrm{p}}$ is the penalty stiffness parameter [74]. $T_{1}$ is the normal traction calculated by reducing the measured normal strength $\sigma_{22}$ (Table 2). According to [74] $T_{1}$ is related to the number of elements applied in the cohesive zone. Thus, the reduction of interface normal strength has been performed in order to ensure enough number of elements in the cohesive zone (element size $l_{\mathrm{e}}=0.75 \mathrm{~mm}$ ) and to improve the convergence rate of the solution. M4 interface normal strength has been assumed equal to that of $\mathrm{M} 1$, since no $90^{\circ} \mathrm{M} 4$ specimens have been tested in the material characterization process (Table 2).

In both FE formulations, the constitutive behavior of the cohesive elements is in the context of Damage Mechanics. The main difference between them is that Alya uses a bilinear softening law (traction-separation) [22], while MSC MARC uses an exponential damage law [61].

With regards to the MMB test simulation, Alya uses the Benzeggagh Kenane approach [75] for the critical energy release rate $G_{c}$,

$$
G_{c}=G_{l c}+\left(G_{\text {Ilc }}-G_{\mathrm{Ic}}\right)\left(\frac{G_{\text {shear }}}{G_{\mathrm{T}}}\right)^{\eta}
$$

where

$$
G_{\text {shear }}=G_{\|}+G_{\| I}
$$

and

$$
G_{T}=G_{1}+G_{\text {shear }}
$$

As the mixed mode bending tests performed in this study only account for fracture Modes I and II, the cohesive zone model is based on the assumption that $G_{\| I I}=G_{\|}$. The Benzeggagh-Kenane parameter has been taken as $\eta=1.75$ based on a parametric study.

For consistency, same dimensions and mesh have been used for all models. In the case of MSC MARC the FE tests have been modelled in 2-d for the sake of simplicity, while in Alya in full 3-d. MSC MARC uses plane strain full integration elements (type 11) to define the bulk material and cohesive elements (type 186) for modelling the interface. On the other hand, Alya uses 3-d in-house solid elements to model the bulk material and cohesive elements for the interface. All models have an element size of $0.15 \mathrm{~mm}$ along the length of the specimen; DCB model has 4 elements through the thickness and ENF, MMB have 5 due to the difference in thickness; for the 3-d models 
7 elements are used through width of the DCB and 9 for the ENF and MMB tests. It is worth mentioning that for the ENF test pre-damaged cohesive elements have been placed at the pre-crack interface in order to avoid penetration between the two arms.

\section{Results and Discussion}

The ILFT of the composite material systems studied is provided in terms of strain energy release rate for each mode respectively: $G_{\mathrm{Ic}}$ (Mode I), $G_{\| \mathrm{lc}}$ (Mode II) and $G_{c}$ (Mode I/II). Components involved in the fracture toughness evaluation process are also reported in order to provide complete overview of the material behavior and validation data for new tests to be performed in the open literature. Wherever practical, experimental results are provided by mean value and coefficient of variance, while load-transverse displacement data are explicitly compared to analytical and numerical predictions. Analytical predictions are presented for loading without crack growth, indicated as LEFM lin, and for crack propagation (LEFM prop). In the graphs presenting experimental data, specimen indication follows a 4-index convention: index 1 is $C$ or $C d$ for control or doped composite laminate, respectively, index 2 is none or HW for non-aged or aged specimens, respectively, index 3 is I, II or I/II depending on the fracture mode considered and index 4 denotes specimen number.

\subsection{Composite Ply Properties}

The experimentally determined mechanical properties at the composite ply level are provided for the RT material systems in Table 2. Mechanical properties evaluated after conditioning (HW) are shown in Table 3.

\begin{tabular}{|c|c|c|c|c|c|}
\hline \multirow[t]{2}{*}{ Test } & \multirow[t]{2}{*}{ Property } & \multicolumn{2}{|c|}{ M1 (C) } & \multicolumn{2}{|c|}{ M4 (Cd) } \\
\hline & & Mean Value & $\begin{array}{l}\text { Coefficient of } \\
\text { Variance (\%) }\end{array}$ & Mean Value & $\begin{array}{l}\text { Coefficient of } \\
\text { Variance }(\%)\end{array}$ \\
\hline \multirow{3}{*}{ Tension 0 [67] } & $E_{11}^{\top}(\mathrm{GPa})$ & 138.4 & 1.95 & 133.8 & 6.03 \\
\hline & $V_{12}$ & 0.31 & 15.70 & 0.33 & 4.70 \\
\hline & $\sigma_{11} \mathrm{UT}^{(\mathrm{MPa})}$ & 2850 & 4.00 & 2370 & 4.10 \\
\hline \multirow{2}{*}{$\begin{array}{c}\text { Tension } 90 \\
{[67]}\end{array}$} & $E_{22}^{\top}(\mathrm{GPa})$ & 8.54 & 3.00 & - & - \\
\hline & $\sigma_{22}{ }^{\mathrm{UT}}(\mathrm{MPa})$ & 56.6 & 5.84 & - & - \\
\hline \multirow{2}{*}{$\begin{array}{c}\text { Compression } \\
0 \text { [68-69] }\end{array}$} & $E_{11^{C}}(\mathrm{GPa})$ & 141.2 & 3.37 & 130.2 & 2.51 \\
\hline & $\sigma_{11} \mathrm{UC}(\mathrm{MPa})$ & 1109 & 13 & - & - \\
\hline \multirow{2}{*}{$\begin{array}{c}\text { Compression } \\
90[68]\end{array}$} & $E_{22}{ }^{\mathrm{C}}(\mathrm{GPa})$ & 8.71 & 2.06 & - & - \\
\hline & $\sigma_{22} \mathrm{UC}(\mathrm{MPa})$ & 158 & 4 & & \\
\hline \multirow{3}{*}{$\begin{array}{l}\text { In-Plane } \\
\text { Shear [70] }\end{array}$} & $G_{12}(\mathrm{GPa})$ & 4.3 & 3.00 & - & - \\
\hline & $\sigma_{12} 0.2 \%(\mathrm{MPa})$ & 48.2 & 3.29 & - & - \\
\hline & $\sigma_{12} \mathrm{U}(\mathrm{MPa})$ & 125 & 2.09 & - & - \\
\hline ILSS [71] & $T^{\mathrm{U}}(\mathrm{MPa})$ & 93.7 & 0.58 & 94.3 & 1.59 \\
\hline \multirow{2}{*}{ Flexure [72] } & $E_{11} \mathrm{~F}(\mathrm{GPa})$ & 134.2 & 1.06 & - & - \\
\hline & $\sigma_{11} \mathrm{UF}(\mathrm{MPa})$ & 1220 & 1.33 & - & - \\
\hline
\end{tabular}

Table 2: Measured mechanical properties of RT material systems considered (C: composite, Cd: doped composite). 


\begin{tabular}{|c|c|c|c|c|c|}
\hline \multirow[t]{2}{*}{ Test } & \multirow[t]{2}{*}{ Property } & \multicolumn{2}{|c|}{ M1 (C) } & \multicolumn{2}{|c|}{ M4 (Cd) } \\
\hline & & Mean Value & $\begin{array}{l}\text { Coefficient of } \\
\text { Variance }(\%)\end{array}$ & Mean Value & $\begin{array}{l}\text { Coefficient of } \\
\text { Variance (\%) }\end{array}$ \\
\hline \multirow{3}{*}{$\begin{array}{c}\text { Tension } 0 \\
{[61]}\end{array}$} & $E_{11}^{\top}(\mathrm{GPa})$ & 143 & 2 & 139 & 1 \\
\hline & $v_{12}$ & 0.314 & 2 & 0.310 & 5 \\
\hline & $\sigma_{11} \mathrm{UT}(\mathrm{MPa})$ & 2800 & 5 & 2500 & 2 \\
\hline \multirow{2}{*}{$\begin{array}{c}\text { Tension } 90 \\
{[61]}\end{array}$} & $E_{22}^{\top}(\mathrm{GPa})$ & 7.42 & 0.4 & - & - \\
\hline & $\sigma_{22} \mathrm{UT}^{(\mathrm{MPa})}$ & 34.2 & 8 & - & - \\
\hline \multirow{2}{*}{$\begin{array}{c}\text { Compression } \\
0[68]\end{array}$} & $E_{11}{ }^{\mathrm{C}}(\mathrm{GPa})$ & 138 & 2 & 136 & 1 \\
\hline & $\sigma_{11} \mathrm{UC}(\mathrm{MPa})$ & 994 & 5 & 690 & 6.8 \\
\hline \multirow{2}{*}{$\begin{array}{c}\text { Compression } \\
90[68]\end{array}$} & $E_{22}{ }^{\mathrm{C}}(\mathrm{GPa})$ & 8.45 & 3 & - & - \\
\hline & $\sigma_{22}{ }^{\mathrm{UC}}(\mathrm{MPa})$ & 115 & 2 & - & - \\
\hline \multirow{3}{*}{$\begin{array}{l}\text { In-Plane } \\
\text { Shear [70] }\end{array}$} & $G_{12}(\mathrm{GPa})$ & 3.79 & 8 & - & - \\
\hline & $\sigma_{12}{ }^{0.2 \%}(\mathrm{MPa})$ & 36.5 & 4 & - & - \\
\hline & $\sigma_{12} \mathrm{U}(\mathrm{MPa})$ & 93.5 & 1 & - & - \\
\hline ILSS [71] & $T^{\cup}(\mathrm{MPa})$ & 63.7 & 1 & 44.7 & 8 \\
\hline \multirow{2}{*}{ Flexure [72] } & $E_{11}{ }^{\mathrm{F}}(\mathrm{GPa})$ & 134 & 3 & - & - \\
\hline & $\sigma_{11} \mathrm{UF}(\mathrm{MPa})$ & 941 & 2 & - & - \\
\hline
\end{tabular}

Table 3: Measured mechanical properties of HW material systems considered (C: composite, Cd: CNTdoped composite).

As expected, the incorporation of CNT across the laminate section practically does not affect the fiber-dominated mechanical properties, such as tensile modulus and strength along fiber direction. Matrix dominated properties also remain more or less unaffected in the case of RT specimens. On the other hand, aging has a major degrading effect as far as the strength of matrix- and shear-dominated properties is concerned, such as tension 90 , compression 90 , interlaminar shear strength of both material systems and flexure.

\subsection{Mode I ILFT}

Figure 6 and Figure 7 illustrate measured and predicted load-displacement curves for control and doped laminate specimens, respectively, at the reloading stage. In each case the measurements on RT and HW specimens are illustrated, indicating a minor effect of aging on the ILFT of Mode I on the basis of maximum force applied for crack initiation. On the contrary, doping seems to considerably increase fracture toughness for both RT and HW specimens.

Moreover, in Figure 6(a) and Figure 7(a) the measurements have been compared to analytical and numerical predictions. An initial crack propagation of $4 \mathrm{~mm}$ (mean value), measured during initial loading, has been taken into account in the predictions in terms of a longer initial crack. The numerical predictions practically coincide with the analytical solution illustrating high accuracy of the corresponding models. Deviations between predictions and measurements are low in the case of the control laminate, whereas they get higher in the case of the doped laminate. A probable reason for that trend could be the existence of slight non-uniformities attributed to dispersion of the CNTs and the manufacturing process, as indicated by the higher variance observed in the CNT-batch response compared to the control one. However, a proper justification would require information from the material in micro-level by using SEM or other appropriate techniques. Such a study has not been performed in the context of the current work. 


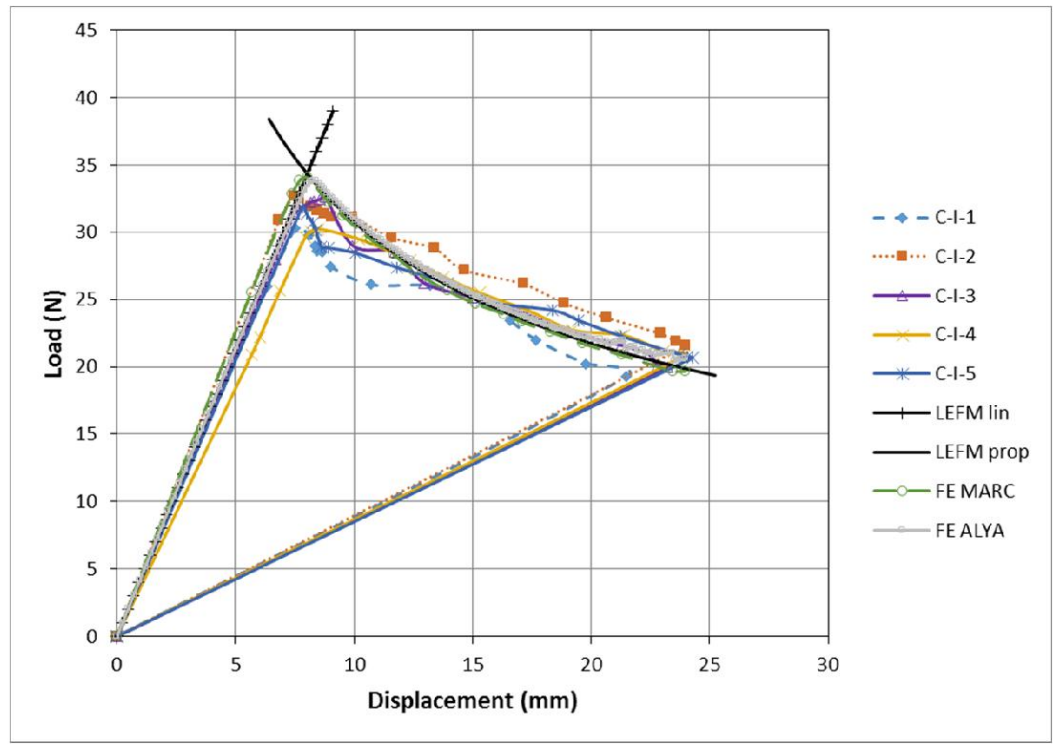

(a)

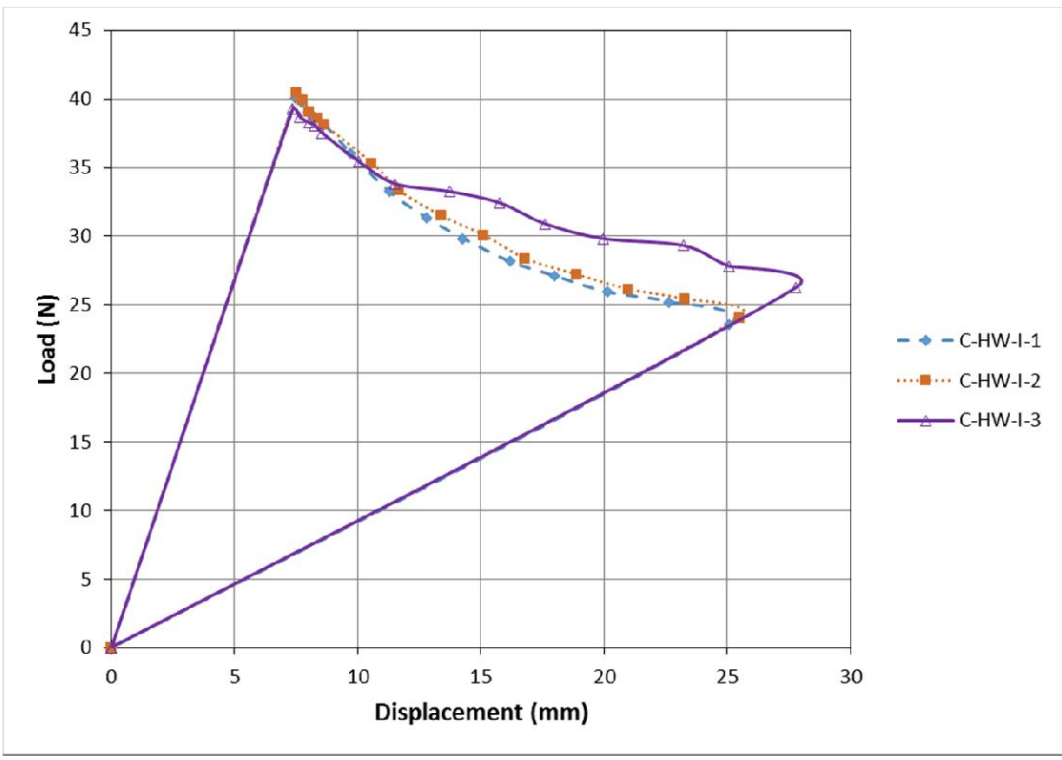

(b)

Figure 6: Transverse load vs opening displacement for M1 composite subjected to Mode I fracture (a) RT specimens, (b) HW specimens. 


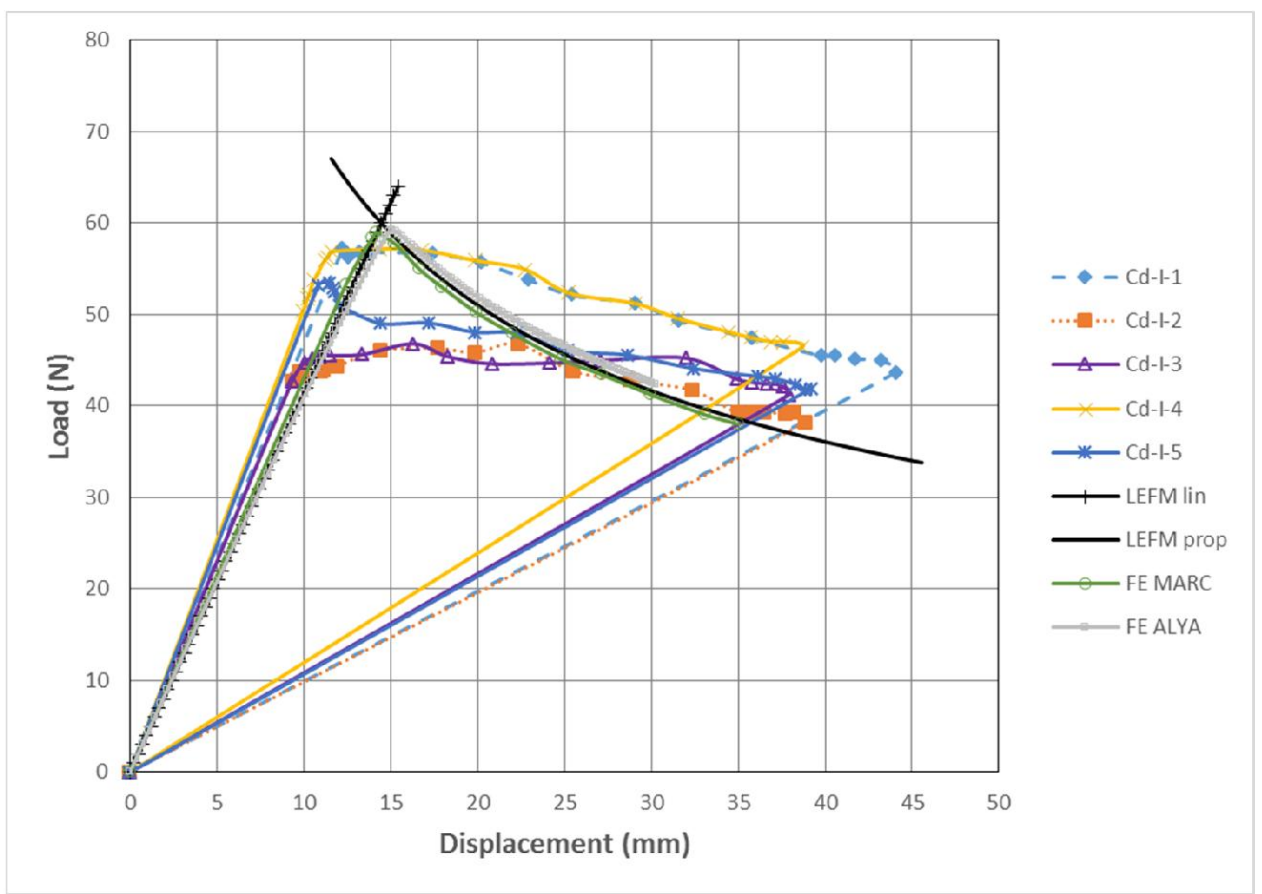

(a)

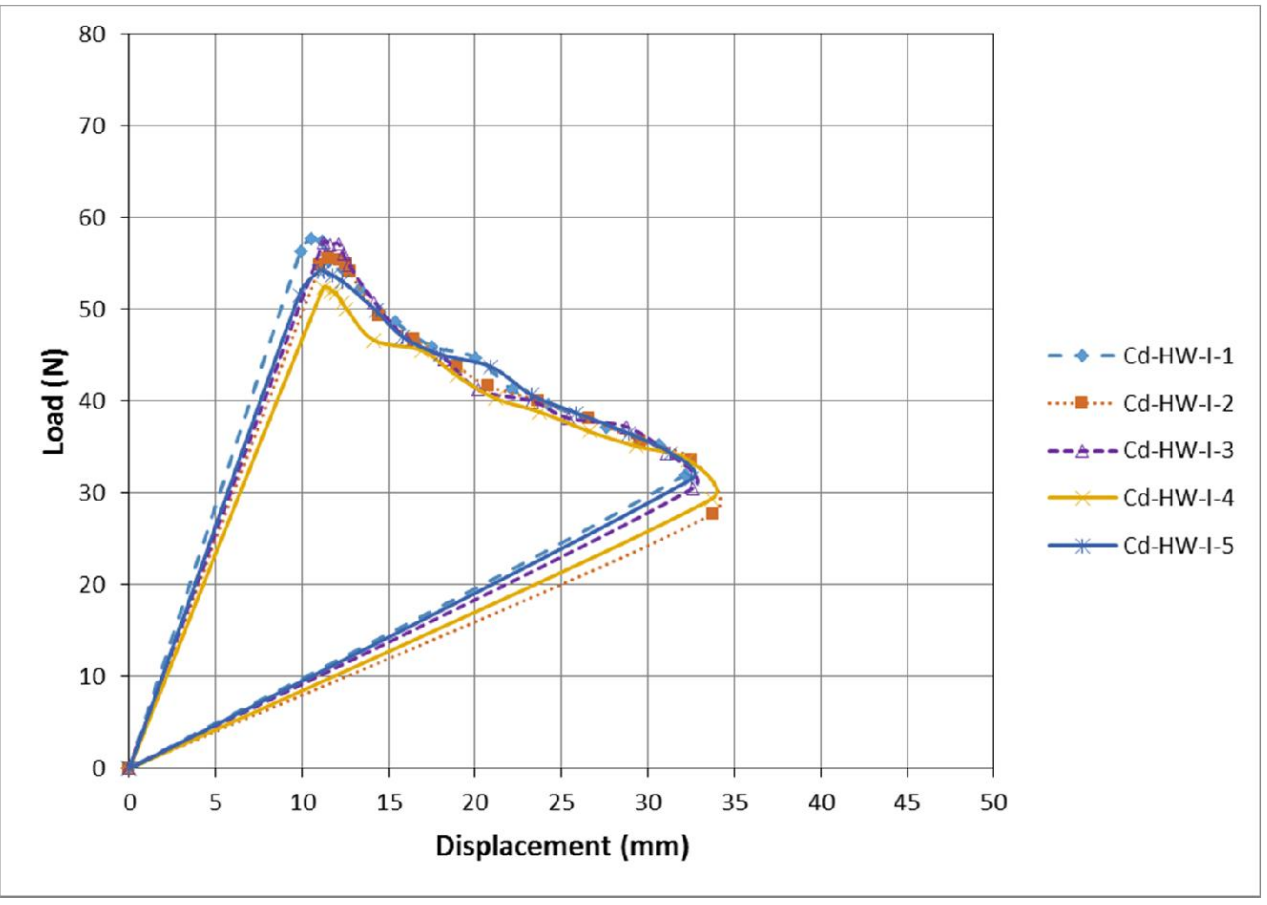

(b)

Figure 7: Transverse load vs opening displacement for M4 composite subjected to Mode I fracture (a) RT specimens, (b) HW specimens.

In Figure 8 and Figure 9 the effect of aging on Mode I ILFT of the two composite materials systems is experimentally quantified in terms of strain energy release rate as a function of delamination length. The aged specimens yield slightly higher fracture toughness than the non-aged ones, as also observed in the preceding loaddisplacement curves. This trend may be attributed to a more compliant behavior (plasticization) of the matrix due to moisture absorption in contradiction to the brittle behavior of the matrix in the case of RT specimens. A similar explanation could be 
provided for the fact that in both non-aged systems ILFT rises with crack length at the initial stage of propagation to eventually reach a plateau, while aging leads to a rather insensitive fracture toughness with respect to crack propagation.

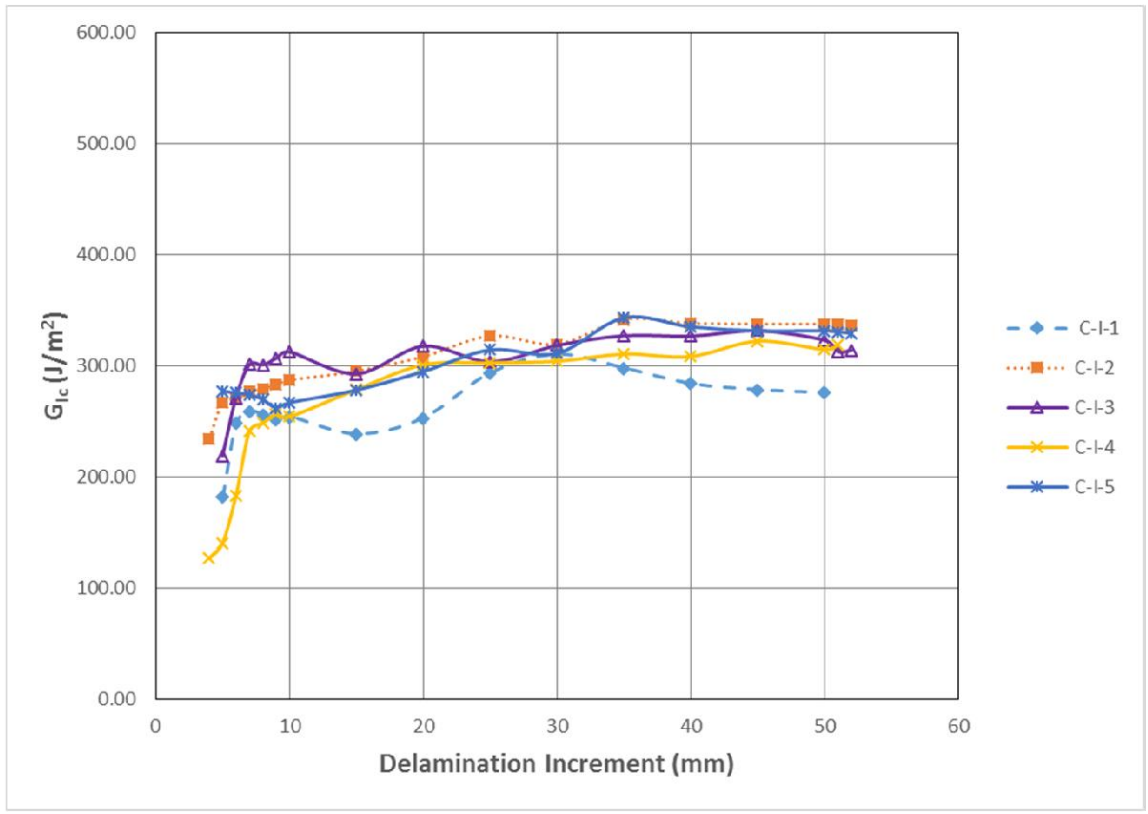

(a)

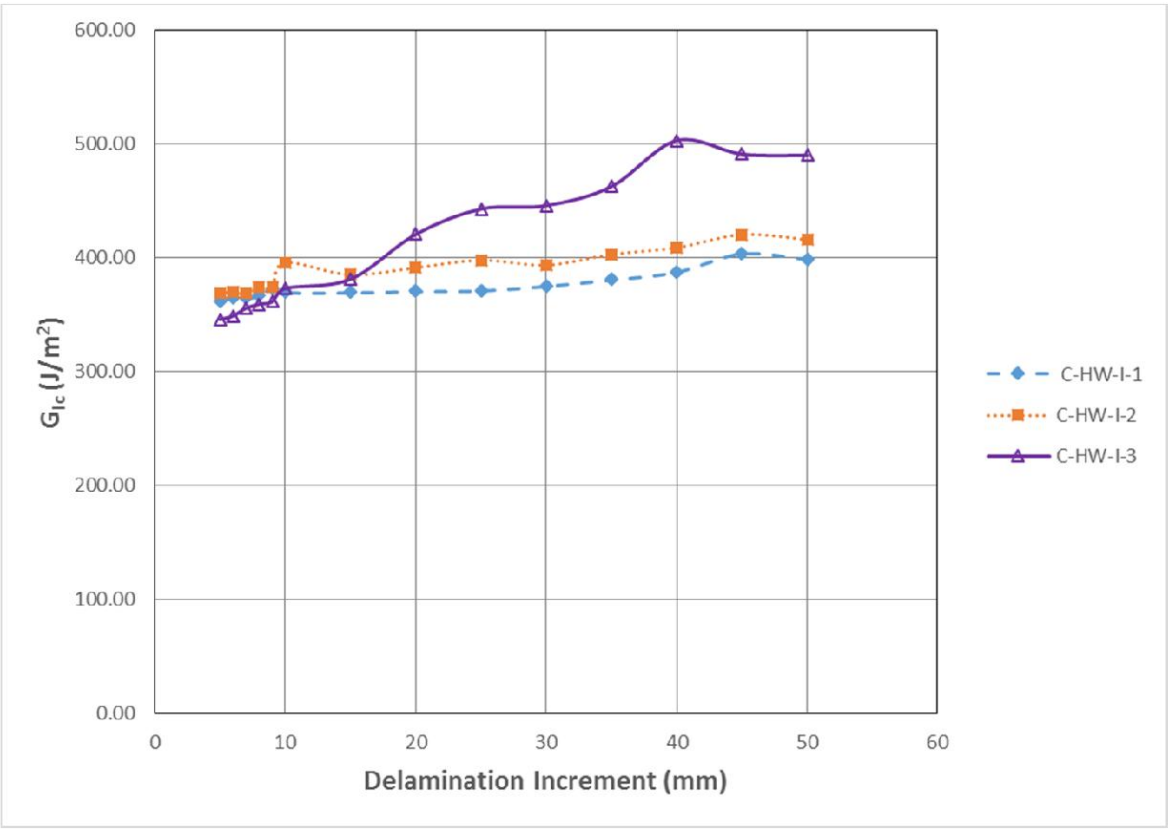

(b)

Figure 8: Effect of aging on Mode I strain energy release rate of M1 composite: (a) RT specimens, (b) HW specimens. 


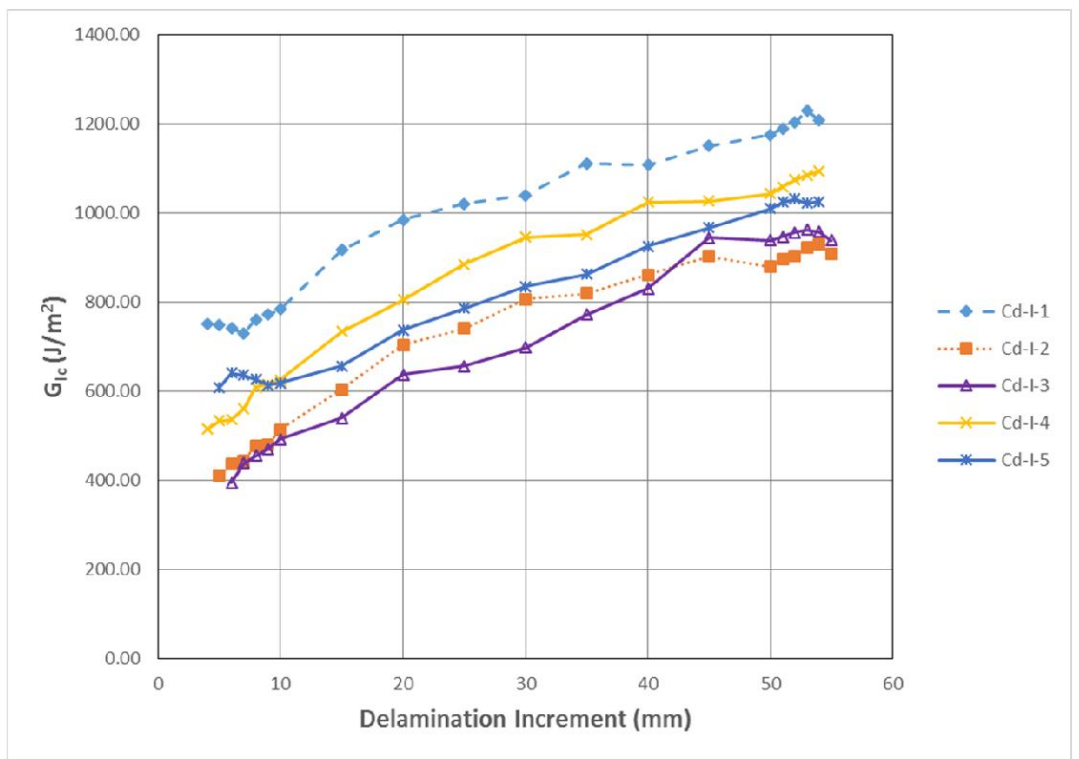

(a)

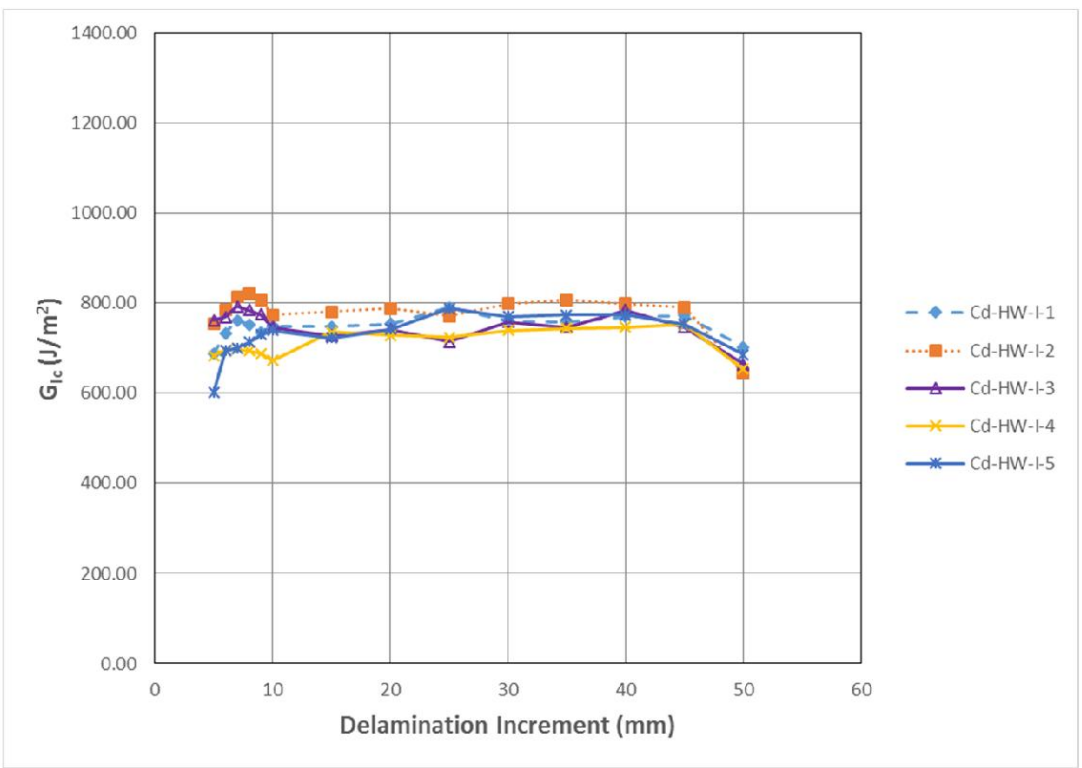

(b)

Figure 9: Effect of aging on Mode I strain energy release rate of M4 composite: (a) RT specimens, (b) HW specimens.

On the basis of Figure 8(a), which illustrates a non-constant relation of $\mathrm{G}_{\mathrm{Ic}}$ with crack propagation, the determination of ILFT for each specimen, as a single value to be used as input in the FE models, is based on the method described in [9]: $\mathrm{G}_{\mathrm{Ic}}$ is the mean of either the last ten values or the last $50 \%$ of all values, whichever contains the larger number of data points. The input value in the FE model is the mean $G_{l c}$ value extracted from all specimens.

The experimentally determined $\mathrm{x}$-intersect $\Delta$ of the curve relating compliance cube root vs crack length [13], which is involved in the evaluation of $G_{\mathrm{c}}$, is listed in Table 4 and Table 5 for RT and HW material systems, respectively, along with the respective correlation coefficient for each specimen. 


\begin{tabular}{|c|c|c|c|c|c|}
\hline $\begin{array}{c}\text { Composite } \\
\text { System }\end{array}$ & specimen & $\Delta(\mathrm{mm})$ & $\mathrm{R}^{2}$ & $\Delta_{\text {mean }}(\mathrm{mm})$ & CV (\%) \\
\hline \multirow{5}{*}{$\sum$} & C-I-1 & -10.48 & 0.994 & \multirow{5}{*}{-10.26} & \multirow{5}{*}{26} \\
\hline & C-I-2 & -11.07 & 0.996 & & \\
\hline & C-I-3 & -6.22 & 0.999 & & \\
\hline & C-I-4 & -13.67 & 0.995 & & \\
\hline & C-I-5 & -9.84 & 0.999 & & \\
\hline \multirow{5}{*}{$\stackrel{\nabla}{\Sigma}$} & Cd-I-1 & -14.31 & 0.998 & \multirow{5}{*}{-15.61} & \multirow{5}{*}{11} \\
\hline & Cd-I-2 & -15.64 & 0.999 & & \\
\hline & Cd-I-3 & -17.56 & 0.999 & & \\
\hline & Cd-I-4 & -16.98 & 0.995 & & \\
\hline & Cd-I-5 & -13.57 & 0.999 & & \\
\hline
\end{tabular}

Table 4: Cube-root compliance vs delamination length fitting parameters for the two RT composite material systems

\begin{tabular}{|c|c|c|c|c|c|}
\hline $\begin{array}{c}\text { Composite } \\
\text { System }\end{array}$ & specimen & $\Delta(\mathrm{mm})$ & $\mathrm{R}^{2}$ & $\Delta_{\text {mean }}(\mathrm{mm})$ & CV (\%) \\
\hline \multirow{3}{*}{$\sum$} & C-I-1 & -5.04 & 0.9993 & \multirow{3}{*}{-5.96} & \multirow{3}{*}{14} \\
\hline & C-I-2 & -6.20 & 0.9993 & & \\
\hline & C-I-3 & -6.65 & 0.9996 & & \\
\hline \multirow{5}{*}{$\stackrel{\nabla}{\Sigma}$} & Cd-I-1 & -3.39 & 0.9988 & \multirow{5}{*}{-4.77} & \multirow{5}{*}{43} \\
\hline & Cd-I-2 & -1.88 & 0.9958 & & \\
\hline & Cd-I-3 & -6.28 & 0.9992 & & \\
\hline & Cd-I-4 & -6.39 & 0.9991 & & \\
\hline & Cd-I-5 & -5.92 & 0.9993 & & \\
\hline
\end{tabular}

Table 5: Cube-root compliance vs delamination length fitting parameters for the two HW composite material systems

Possible causes of the low sensitivity of ILFT to crack propagation in aged M1 coupons can be deduced from fractography (macrophotography) images, shown in Figure 10. In the case of M1 RT parabolic fringes could be observed, indicating non-uniform bending of the specimen's half parts (up and low) along the width. Thus, it may be concluded that in the middle along width there was more deflection than near the free edges, meaning that the delamination started from the center and spread towards outer faces. This trend is more obvious near the Teflon tape, whereas the slope of the fringes decreases significantly as we move away from the Teflon tape along the length of the specimen. On that basis, the form of the curve for the M1 RT tests may be explained (high slope in the beginning, little or no slope after some propagation). In the case of M1 HW specimens no fringes have been observed, indicating a rather stable crack propagation throughout the DCB test. In the case of M4 (RT and HW), the matrix appears to be denser and blurred compared to M1 due to the presence of the CNTs. The surface is rougher than in the case of M1, indicating higher fracture toughness [39].

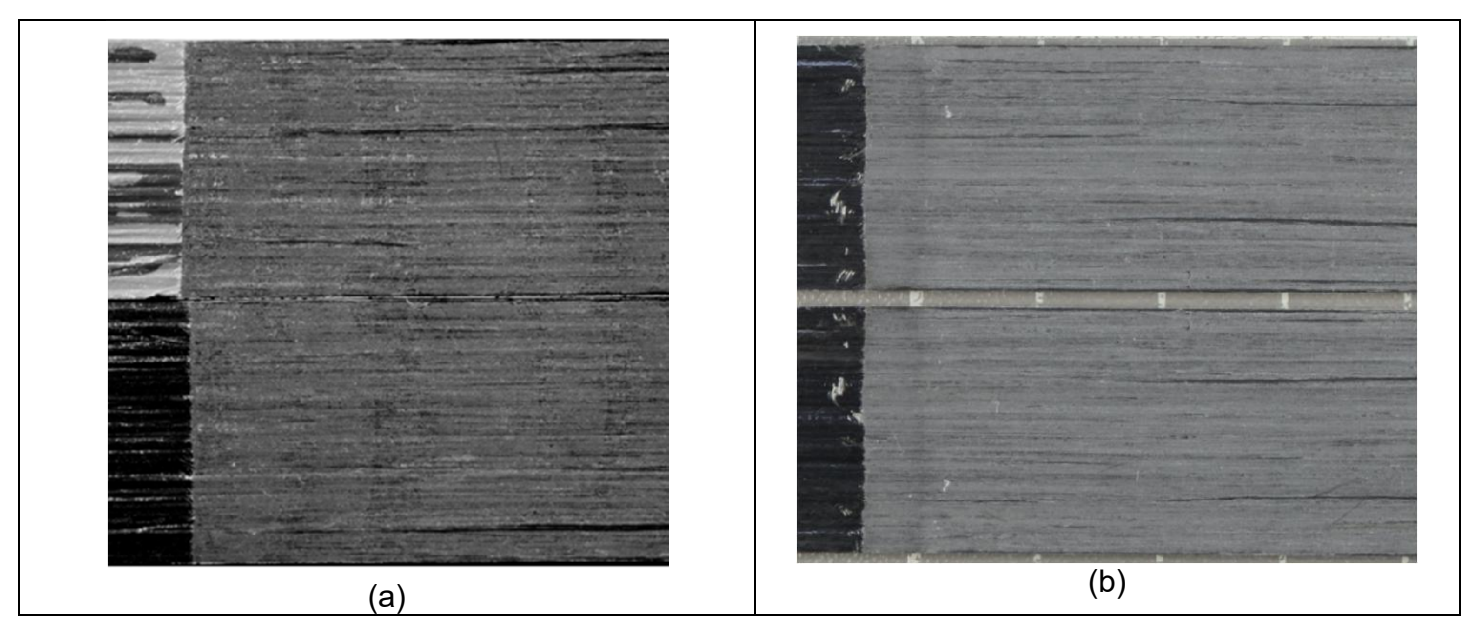




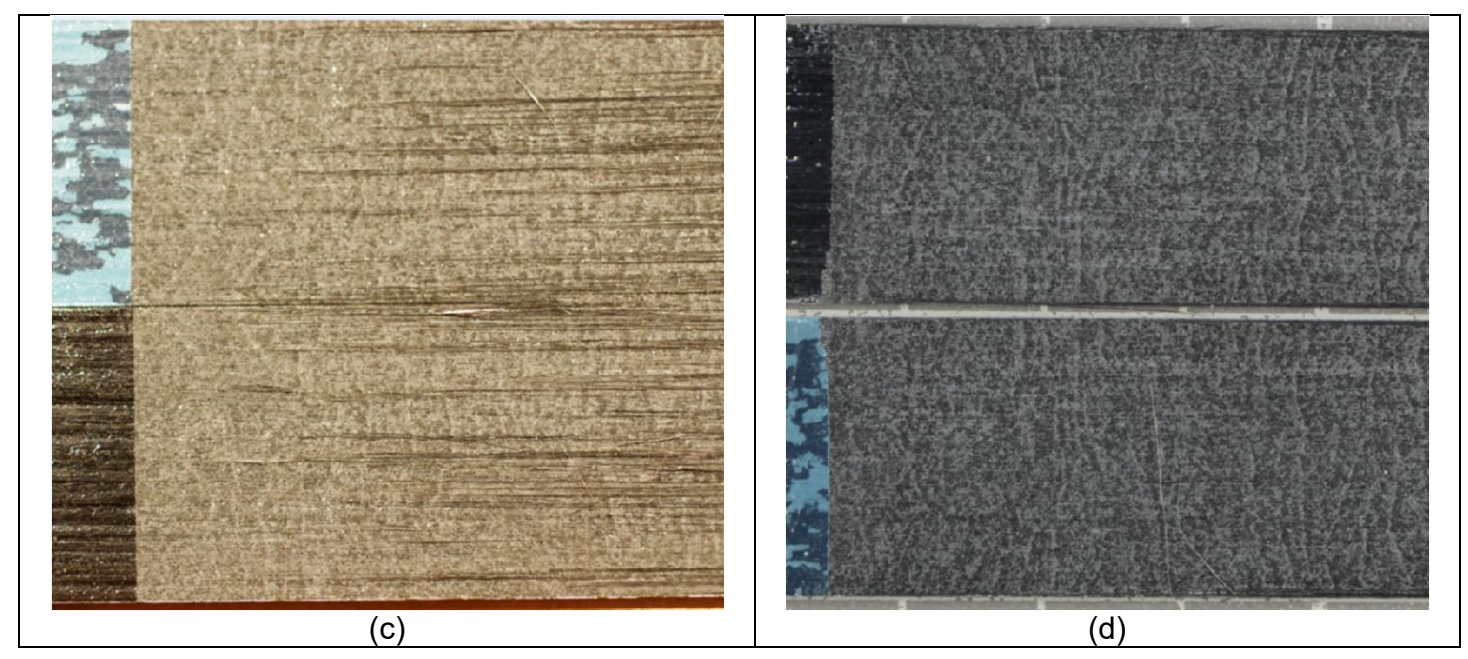

Figure 10: Indicative fractography images of DCB specimens (300 dpi resolution): (a) M1 RT, (b) M1 HW, (c) M4 RT, (d) M4 HW.

Regarding the effect of doping on fracture toughness, ILFT of the doped composite is approximately double compared to the pure composite material system, indicating a trend that has not been traceable from measurement of the ply properties reported in 7.1. Comparison with the response observed in laminates having a CNT-forest applied on the interface between adjacent plies along the crack front [39] reveals a slightly higher increase in ILFT as an average of the batch initial value for crack propagation and an opposite trend of ILFT with crack length. Since CNT-forests work analog to stitching or z-pinning, it could be concluded that the ILFT increase with crack length, which is observed in the current configuration, is mainly attributed to in-plane effects at the crack front. Moreover, the doped material system is more sensitive to aging in further stages of crack propagation, since there is a decrease of approximately $20 \%$ in its fracture toughness at the last stage of crack propagation $(45<a<50 \mathrm{~mm})$. This decrease may be attributed to a rapid loss of stiffness of the interface, since the remaining length of DCB specimen having full thickness is small. However, it should be noted that this trend has been observed exclusively in M4 HW specimens, indicating that, compared to $\mathrm{M} 1$, the CNT-doped laminate is more sensitive to matrix plasticization effects at the crack front at the last stage of crack propagation.

\subsection{Mode II ILFT}

Figure 11(a)-(b) illustrate measured load-displacement curves for RT and HW control laminate specimens, respectively, at the $\mathrm{PC}$ (pre-crack) fracture $\left(\mathrm{a}_{0}=30 \mathrm{~mm}\right)$ loading stage. Similar to Mode I, the mean load for crack propagation is rather insensitive to aging, whereas there is a much lower variance in the case of the aged coupons. Since fracture Mode II is a shear- and thus matrix-dominated load case, the lower variance in the HW specimens could be attributed to smoothing matrix inhomogeneity, present at RT, by HW treatment. 


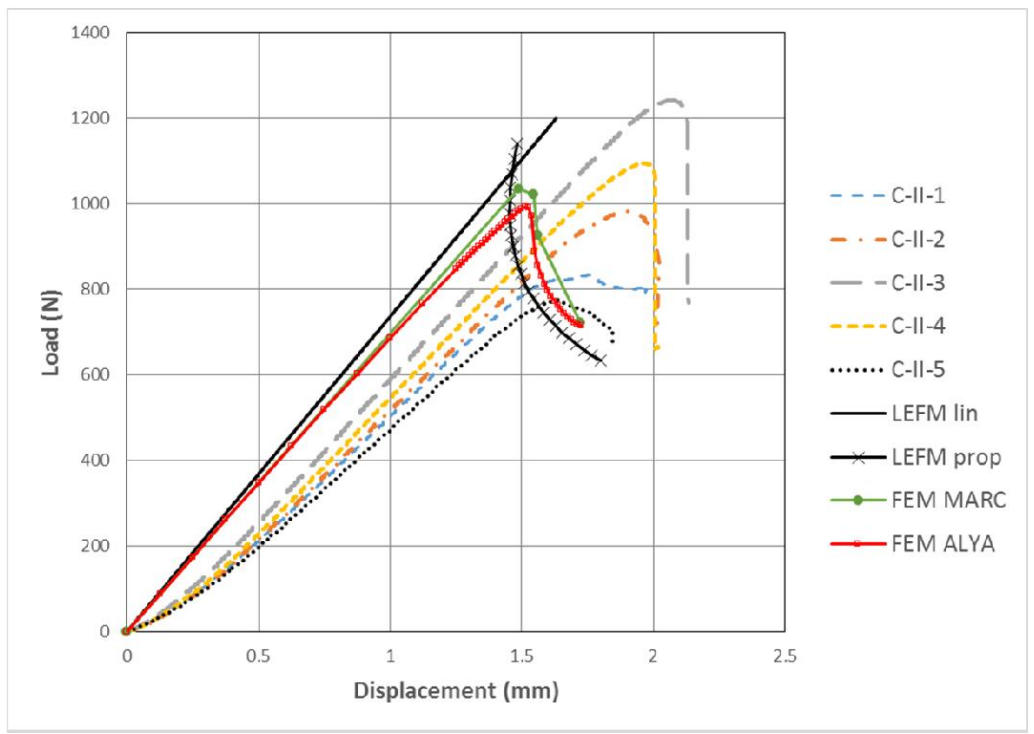

(a)

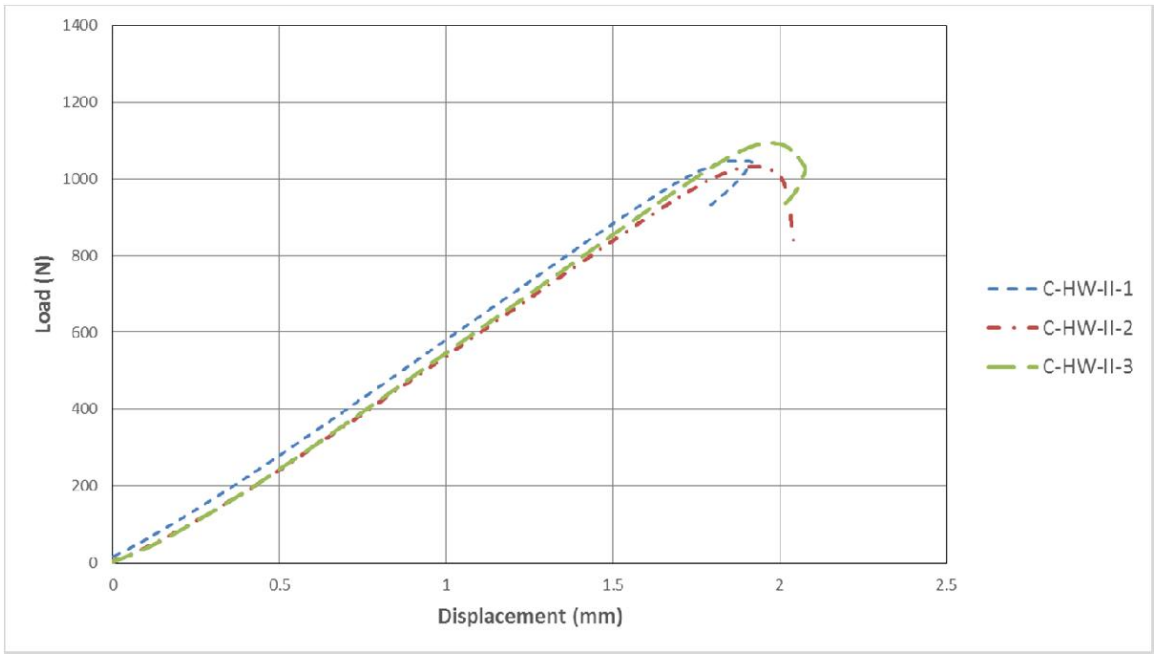

(b)

Figure 11: Effect of aging on ILFT response of M1 composite in Mode II for the PC fracture loading stage: a) RT specimens, b) HW specimens.

Similar trends may be observed in the measured curves for the CNT-doped material system (Figure 12(a)-(b)). 


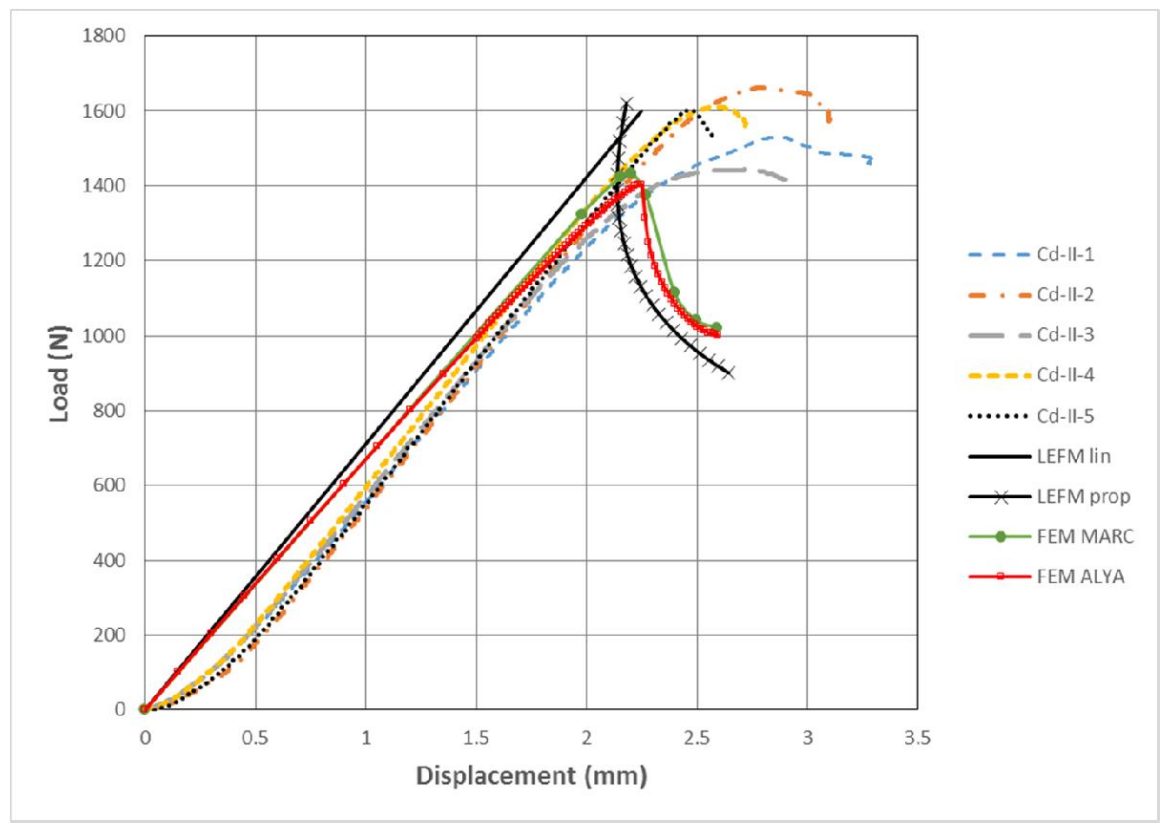

(a)

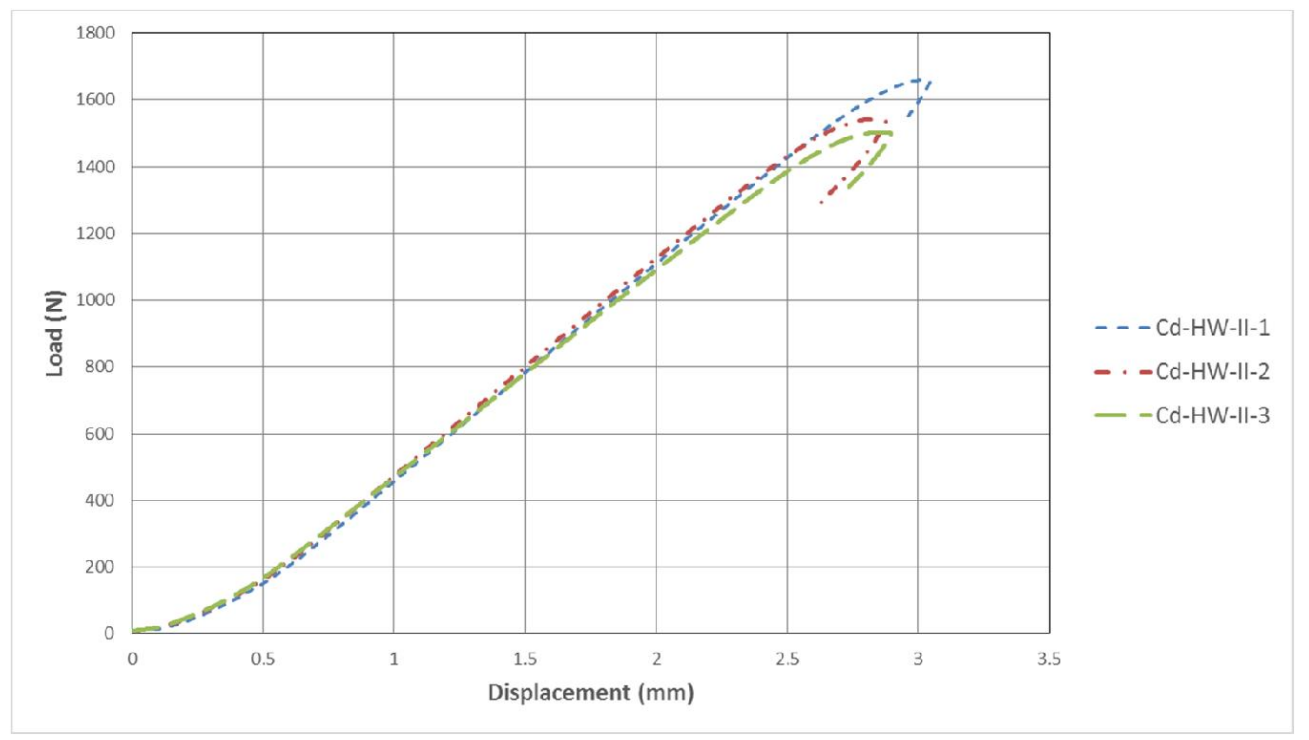

(b)

Figure 12: Effect of aging on ILFT response of M4 composite in Mode II for the PC fracture loading stage: a) RT specimens, b) HW specimens.

In both Figure 11 and Figure 12 at the initial loading stage the load-displacement curves are non-linear. This non-linearity is most probably attributed to the combination of 3-point bending simply-supported setup, evolution of loading nose-specimen contact surface and specimen span to thickness ratio. However, it should be noted that the ASTM 7905 standard accounts for this non-linear response by excluding measured loads lower than $90 \mathrm{~N}$ in all measuring stages (NPC and PC).

As far as the effect of CNT-doping on fracture toughness is concerned, the inclusion of the CNTs leads to a $30 \%$ increase in maximum load before unstable crack propagation. This trend is in agreement with observations reported in literature $[39,47]$ and is mainly attributed to matrix enhancement in terms of shear fracture toughness through inclusion of CNTs. 
Regarding numerical predictions, both FE models give fairly good estimations for onset and propagation of delamination in the case of the control laminate, whereas in the case of the CNT-doped laminate they seem to underestimate the slope of the loaddisplacement curve and the maximum load. However, comparison of FE predictions with the analytical solutions reveal that deviations in slope mainly deal with the interfacial properties assumed in the FE models (Table 1) rather than with mechanical properties or element type. In general terms, the maximum load is underpredicted for all materials and then, a load drop occurs with some snap-back. This fact is not surprising for this kind of materials since it is rather unusual for this test to have a stable crack growth.

In Figure 13 the Mode II ILFT of the two composite materials systems is quantified in terms of strain energy release rate $\left(G_{\| c}\right)$ as mean value with standard deviation for the NPC (non pre-crack) and PC loading stages. It can be concluded that the inclusion of CNTs leads to $100 \%$ increase in Mode II fracture toughness in the PC loading stage. It should be noted that for determining $G_{\| c}$ the measured flexural modulus of the control material (section 7.1) has been used. The trend in fracture toughness is similar to other CNT-doping techniques: In the case of doped laminates with a CNT-forest at the crack interface [39] the enhancement of ILFT in Mode II is 161\%, whereas for CNT-grafted laminates it is $53 \%$ [47]. Moreover, in the current case crack propagation is sudden and fast, indicating a rather brittle response in both control and doped laminates. Other doping methods, such as CNT-grafting [47], have been reported to lead to a more ductile behavior due to enhancement of friction between adjacent laminas.

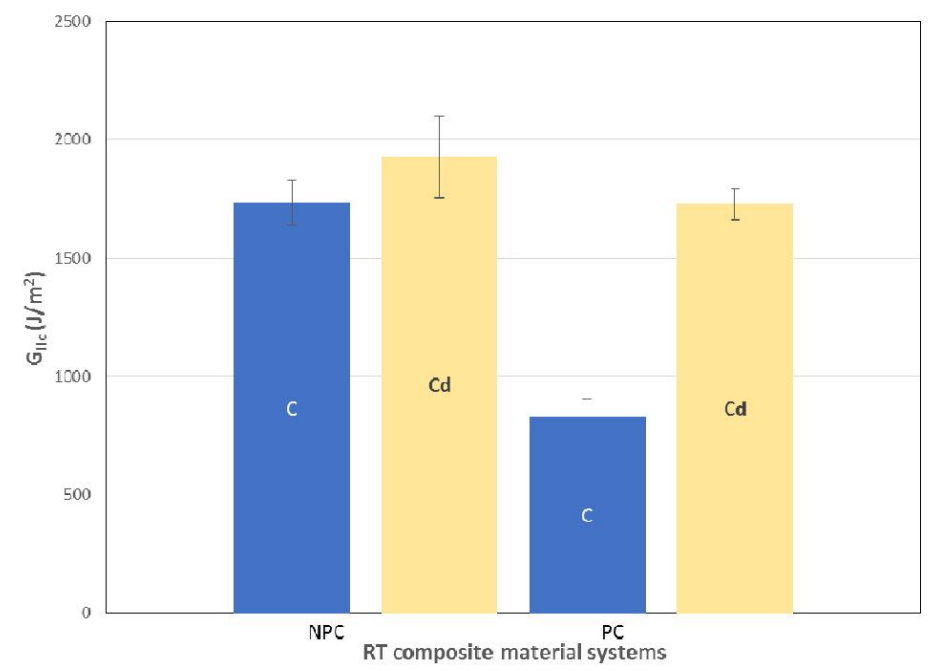

Figure 13: Histogram of strain energy release rate in Mode II ( $\left.\mathrm{G}_{\| \mathrm{lc}}\right)$ of RT M1 (C) and M4 (Cd) laminates for NPC and PC loading stages

Similar conclusions may be extracted from Figure 14, where the effect of CNT-doping on aged coupons is presented. It is interesting that for both aged and non-aged material systems, a larger increase in fracture toughness is evident at PC loading stage, i.e. after the initial crack tip opening (occurring at NPC). This trend may be attributed to the absence of fiber bridging at the PC loading stage, which allows for the matrix-dominated effects to prevail during loading. Moreover, the aged system yields higher fracture toughness, especially at the PC stage, than the non-aged. That point may be attributed to matrix plasticization due to conditioning, which results in a more stable crack propagation during the 3-point bending tests, as indicated by the smaller variance observed in the load-displacement curves of Figure 12(b). 


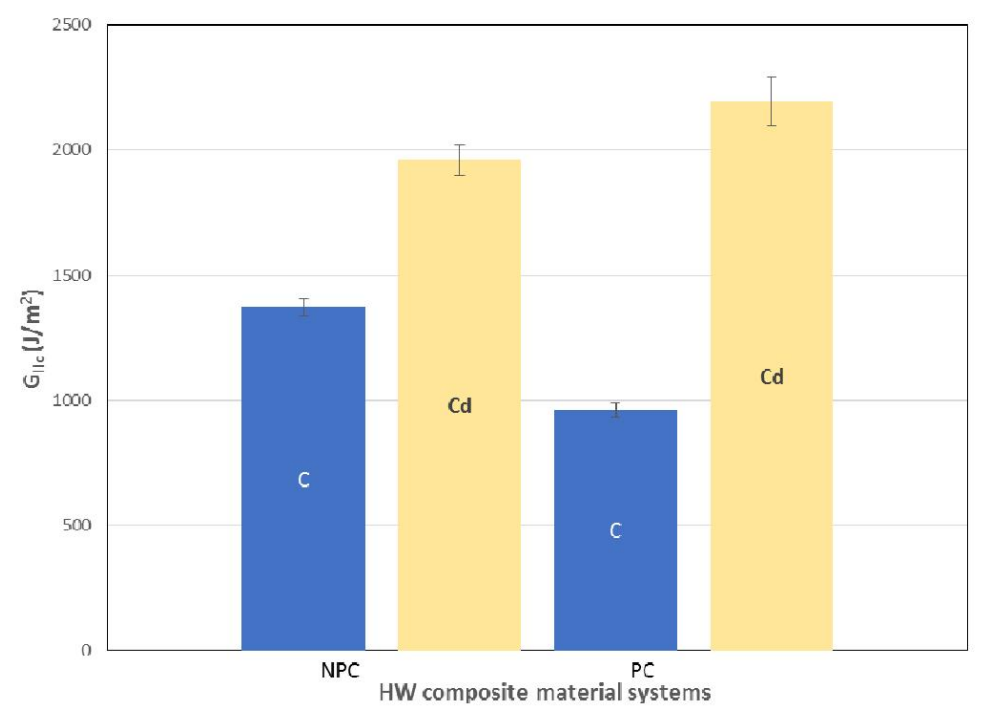

Figure 14: Histogram of strain energy release rate in Mode II (G $\left.G_{I c}\right)$ of HW M1 (C) and M4 (Cd) laminates for NPC and PC loading stages

The fact that the increase in fracture toughness of the aged doped material system at the PC stage is higher than in the aged control laminate (compared to the respective RT values) may probably indicate the involvement of additional complex toughening mechanisms in the case of CNT enriched matrix, such as crack bridging, crack deflection and shear yielding. However, such an in-depth investigation has not been performed in the context of the present work.

A detailed overview of the tests, including compliance for calibration (CC1, CC2) and fracture $\left(\mathrm{C}_{0}, \mathrm{C}_{\mathrm{u}}\right)$, slope of the linear fit of compliance versus crack length cubed data $(m)$, as well as, candidate toughness lowest $\left(G_{Q, 1} \geq 15 \%\right)$ and highest $\left(G_{Q, 2} \leq 35 \%\right)$ percentages evaluation is presented in Table 6 and Table 7 for NPC and PC loading stage, respectively, of the RT specimens. In Table 8 and Table 9 the corresponding values for the HW specimens are listed for NPC and PC loading stage, respectively. 


\begin{tabular}{|c|c|c|c|c|c|c|c|c|c|}
\hline System & specimen & $\begin{array}{c}\text { CC1 } \\
\left(10^{-3} \mathrm{~mm} / \mathrm{N}\right)\end{array}$ & $\begin{array}{c}\mathrm{CC} 2 \\
\left(10^{-3} \mathrm{~mm} / \mathrm{N}\right)\end{array}$ & $\begin{array}{c}C_{0} \\
\left(10^{-3} \mathrm{~mm} / \mathrm{N}\right)\end{array}$ & $\begin{array}{c}\mathrm{C}_{\mathrm{u}} \\
\left(10^{-3} \mathrm{~mm} / \mathrm{N}\right)\end{array}$ & $\begin{array}{c}m \\
\left(10^{-8} \mathrm{~N}^{-1} \mathrm{~mm}^{-2}\right)\end{array}$ & $G_{\| l c}\left(J / m^{2}\right)$ & $\mathrm{G}_{\mathrm{Q}, 1}(\%)$ & $\mathbf{G}_{\mathrm{Q}, 2}(\%)$ \\
\hline \multirow{5}{*}{$\Sigma$} & C-II-1 & 1.36 & 2.13 & 1.60 & 3.53 & 1.39 & 2005 & 20.0 & 20.4 \\
\hline & C-II-2 & 1.35 & 2.13 & 1.62 & 2.94 & 1.40 & 1429 & 28.4 & 29.0 \\
\hline & C-II-3 & 1.35 & 2.17 & 1.62 & 2.90 & 1.48 & 1789 & 22.6 & 22.9 \\
\hline & C-II-4 & 1.34 & 2.12 & 1.60 & 3.06 & 1.41 & 1653 & 24.6 & 24.3 \\
\hline & C-II-5 & 1.36 & 2.14 & 1.60 & 3.43 & 1.40 & 1791 & 17.7 & 16.9 \\
\hline \multirow{5}{*}{$\stackrel{\nabla}{\Sigma}$} & CdA-II-1 & 1.21 & 1.92 & 1.43 & 2.75 & 1.28 & 2136 & 20.8 & 19.5 \\
\hline & CdA-II-2 & 1.25 & 1.92 & 1.45 & 2.58 & 1.22 & 1795 & 24.2 & 24.1 \\
\hline & CdA-II-3 & 1.24 & 1.91 & 1.44 & 2.55 & 1.20 & 1567 & 25.4 & 25.6 \\
\hline & CdA-II-4 & 1.21 & 1.89 & 1.42 & 2.38 & 1.23 & 1639 & 25.1 & 26.2 \\
\hline & CdA-II-5 & 1.16 & 1.88 & 1.37 & 2.13 & 1.30 & 2497 & 17.4 & 17.2 \\
\hline
\end{tabular}

Table 6: Experimentally determined parameters [15] for the two RT composite material systems at NPC loading stage of Mode II fracture test

\begin{tabular}{|c|c|c|c|c|c|c|c|c|}
\hline System & specimen & $\begin{array}{c}\mathrm{CC} 1 \\
\left(10^{-3} \mathrm{~mm} / \mathrm{N}\right)\end{array}$ & $\begin{array}{c}\mathrm{CC2} \\
\left(10^{-3} \mathrm{~mm} / \mathrm{N}\right)\end{array}$ & $\begin{array}{c}\mathrm{C}_{0} \\
\left(10^{-3} \mathrm{~mm} / \mathrm{N}\right)\end{array}$ & $\begin{array}{c}m \\
\left(10^{-8} \mathrm{~N}^{-1} \mathrm{~mm}^{-2}\right)\end{array}$ & $G_{\| l c}\left(J / m^{2}\right)$ & $\mathbf{G}_{Q, 1}(\%)$ & $\mathbf{G}_{Q, 2}(\%)$ \\
\hline \multirow{5}{*}{$\Sigma$} & C-II-1 & 1.40 & 2.43 & 1.80 & 1.83 & 682 & 28.2 & 28.6 \\
\hline & C-II-2 & 1.39 & 2.26 & 1.70 & 1.55 & 799 & 20.6 & 20.9 \\
\hline & C-II-3 & 1.28 & 2.01 & 1.53 & 1.32 & 1092 & 15.2 & 15.1 \\
\hline & C-II-4 & 1.36 & 2.12 & 1.61 & 1.35 & 872 & 16.3 & 16.0 \\
\hline & C-II-5 & 1.44 & 2.55 & 1.86 & 1.96 & 632 & 34.6 & 34.5 \\
\hline \multirow{5}{*}{$\stackrel{\nabla}{\Sigma}$} & CdA-II-1 & 1.21 & 2.04 & 1.49 & 1.49 & 1874 & 28.3 & 29.3 \\
\hline & CdA-II-2 & 1.13 & 1.80 & 1.37 & 1.18 & 1753 & 23.2 & 24.9 \\
\hline & CdA-II-3 & 1.17 & 1.92 & 1.45 & 1.33 & 1483 & 32.1 & 33.6 \\
\hline & CdA-II-4 & 1.15 & 1.85 & 1.38 & 1.27 & 1765 & 23.0 & 24.9 \\
\hline & CdA-II-5 & 1.12 & 1.84 & 1.38 & 1.28 & 1764 & 28.5 & 29.2 \\
\hline
\end{tabular}

Table 7: Experimentally determined parameters [15] for the two RT composite material systems at PC loading stage of Mode II fracture test 


\begin{tabular}{|c|c|c|c|c|c|c|c|c|c|}
\hline System & specimen & $\begin{array}{c}\mathrm{CC1} \\
\left(10^{-3} \mathrm{~mm} / \mathrm{N}\right) \\
\end{array}$ & $\begin{array}{c}\mathrm{CC2} \\
\left(10^{-3} \mathrm{~mm} / \mathrm{N}\right)\end{array}$ & $\begin{array}{c}\mathrm{C}_{0} \\
\left(10^{-3} \mathrm{~mm} / \mathrm{N}\right)\end{array}$ & $\begin{array}{c}\mathrm{Cu}_{\mathrm{u}} \\
\left(10^{-3} \mathrm{~mm} / \mathrm{N}\right)\end{array}$ & $\begin{array}{c}m \\
\left(10^{-8} \mathbf{N}^{-1} \mathrm{~mm}^{-2}\right)\end{array}$ & $G_{\| l c}\left(J / m^{2}\right)$ & $\mathbf{G}_{Q, 1}(\%)$ & $\mathbf{G}_{Q, 2}(\%)$ \\
\hline \multirow{3}{*}{$\sum$} & C-II-1 & 1.381 & 2.222 & 1.665 & 2.752 & 1.50 & 1348 & 17 & 17 \\
\hline & C-II-2 & 1.393 & 2.266 & 1.684 & 2.856 & 1.56 & 1461 & 16 & 16 \\
\hline & C-II-3 & 1.342 & 2.150 & 1.616 & 2.523 & 1.44 & 1306 & 17 & 17 \\
\hline \multirow{3}{*}{$\stackrel{\nabla}{\Sigma}$} & CdA-II-1 & 1.349 & 2.250 & 1.614 & 1.725 & 1.62 & 2108 & 18 & 18 \\
\hline & CdA-II-2 & 1.418 & 2.345 & 1.674 & 1.841 & 1.68 & 1804 & 22 & 22 \\
\hline & CdA-II-3 & 1.375 & 2.340 & 1.665 & 1.808 & 1.74 & 1968 & 21 & 21 \\
\hline
\end{tabular}

Table 8: Experimentally determined parameters [15] for the two HW composite material systems at NPC loading stage of Mode II fracture test

\begin{tabular}{|c|c|c|c|c|c|c|c|c|}
\hline System & specimen & $\begin{array}{c}\mathrm{CC} 1 \\
\left(10^{-3} \mathrm{~mm} / \mathrm{N}\right) \\
\end{array}$ & $\begin{array}{c}\mathrm{CC2} \\
\left(10^{-3} \mathrm{~mm} / \mathrm{N}\right) \\
\end{array}$ & $\begin{array}{c}\mathrm{C}_{0} \\
\left(10^{-3} \mathrm{~mm} / \mathrm{N}\right) \\
\end{array}$ & $\begin{array}{c}m \\
\left(10^{-8} \mathrm{~N}^{-1} \mathrm{~mm}^{-2}\right) \\
\end{array}$ & $G_{\| l c}\left(J / m^{2}\right)$ & $\mathrm{G}_{\mathrm{Q}, 1}(\%)$ & $\mathbf{G}_{Q, 2}(\%)$ \\
\hline \multirow{3}{*}{$\Sigma$} & C-II-1 & 1.383 & 2.267 & 1.717 & 1.57 & 925 & 26 & 26 \\
\hline & C-II-2 & 1.433 & 2.326 & 1.751 & 1.59 & 911 & 27 & 27 \\
\hline & C-II-3 & 1.363 & 2.281 & 1.705 & 1.63 & 1049 & 24 & 24 \\
\hline \multirow{3}{*}{$\stackrel{J}{\Sigma}$} & CdA-II-1 & 1.287 & 2.149 & 1.586 & 1.54 & 2275 & 20 & 20 \\
\hline & CdA-II-2 & 1.393 & 2.228 & 1.643 & 1.50 & 1928 & 19 & 19 \\
\hline & CdA-II-3 & 1.387 & 2.466 & 1.653 & 1.96 & 2387 & 24 & 24 \\
\hline
\end{tabular}

Table 9: Experimentally determined parameters [15] for the two HW composite material systems at PC loading stage of Mode II fracture test 


\subsection{Mode I/II ILFT}

In Figure 15(a)-(b) load-displacement curves are presented for the non-aged and aged control laminate specimens, respectively, during propagation of initial delamination in coupons subjected to mixed mode bending. Lower forces have been required for crack propagation in the case of the aged coupons, while variation in the measured response is much lower than in the RT case for maximum load and slope. Thus, it may be concluded that aging in combination with higher test temperature than RT leads to a more compliant and more uniform matrix behavior due to plasticization phenomena.

The MMB response of the RT coupons has been also analytically and numerically predicted and the predictions have been included in Figure 15(a). While ALYA predictions compare well with the analytical solution, there is considerable deviation to measurements as far as slope and maximum load is concerned. Taking into account the large variation occurring in the test data and the fact that maximum load is strongly dependent on interfacial properties reported in Table 1, some of which have not been measured $\left(T_{1}\right.$ and $\left.K_{p}\right)$ and some others have been experimentally determined with a relatively large variance $\left(\mathrm{G}_{\mathrm{lc}}, \mathrm{G}_{\| \mathrm{c}}\right)$, it seems that this deviation is reasonable. In general regarding material modeling in the $\mathrm{MMB}$ test it should be noted that the basic mechanical tests used for extracting basic material properties (Table 2) or interface properties (Table 1) to be used as reference values for subsequent calculations are based on a "pure mode" approach. Results presented herein for control (Figure 15(a)) and doped laminate (Figure 17(a)) may indicate that when it comes to a mixture of Mode I and II these pure-mode properties should be elaborated for capturing the mixed response.

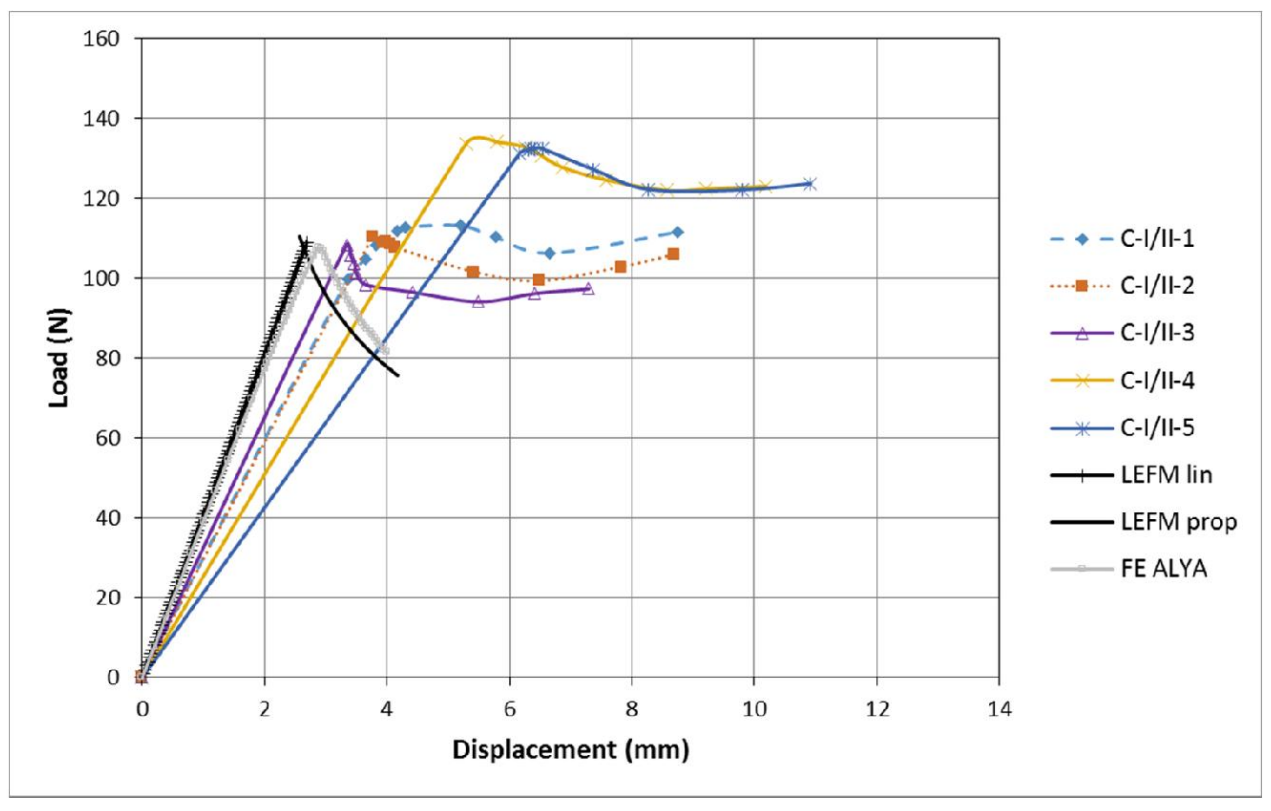

(a) 


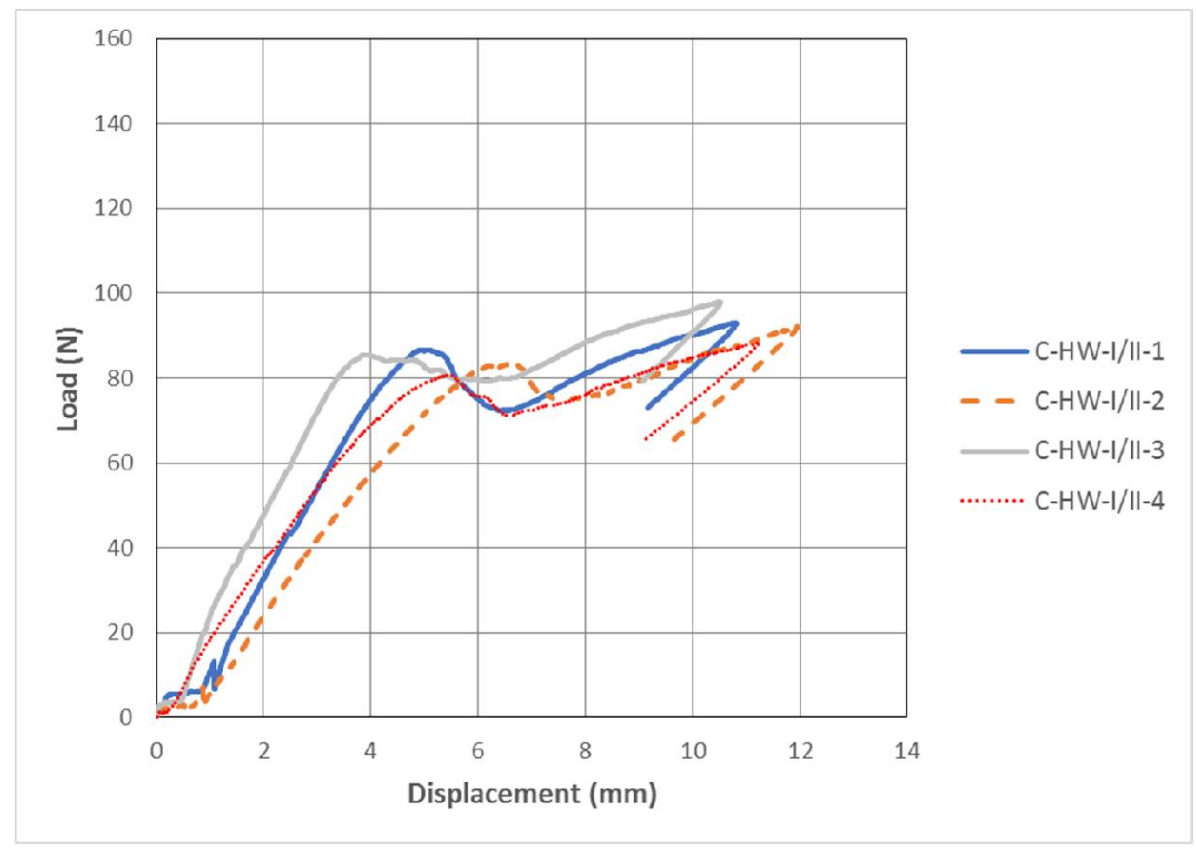

(b)

Figure 15: Transverse load vs opening displacement data during delamination propagation of control laminate subjected to mixed Mode I/II fracture: (a) RT, (b) HW.

Regarding experimental scattering, which is relatively high in this case and in the following case of the doped laminate, it is an evidence of the high sensitivity of the MMB test to material and geometric imperfections, such as a void, specimen or hinge misalignment, as well as to mechanisms at micro-level which could not be identified with the experimental techniques applied in this work. However, from macrophotography images shown in Figure 16 grey areas could be observed, which have different patterns among high slope-low fracture load and low-slope-high fracture load specimens (C-I/II-2 vs C-I/II-5). The pattern observed in specimen 2 may indicate uneven fracture toughness and thus load distribution during crack opening along the width of the specimen. As far as data from published literature is concerned, limited test data have been presented so far in batch mode. From the ones found it seems that it is common in an MMB test to have scattering in the range of $10 \%$ and above ([7], [11] and [76]).



Figure 16: Fractography images of M1 MMB specimens (300 dpi resolution): (a) C-1/II-2, (b) C-I/II-5. 
The load-displacement curves in the case of the CNT-doped material system (Figure 17) reveal that it exhibits higher loads for delamination propagation compared to the control laminate. This trend may be reasonably attributed to the matrix reinforcement with nanotubes. Moreover, crack opening forces are lower in the case of aged coupons, as also observed in the control laminate. However, deviation between analytical-numerical predictions and measurements is higher in that case. The predictions overestimate the maximum load, indicating usage of higher values of interfacial properties (Table 1 ) than the actual ones ( $T_{1}$ of M4 has been assumed to be equal to $T_{1}$ of $\mathrm{M} 1$ ).

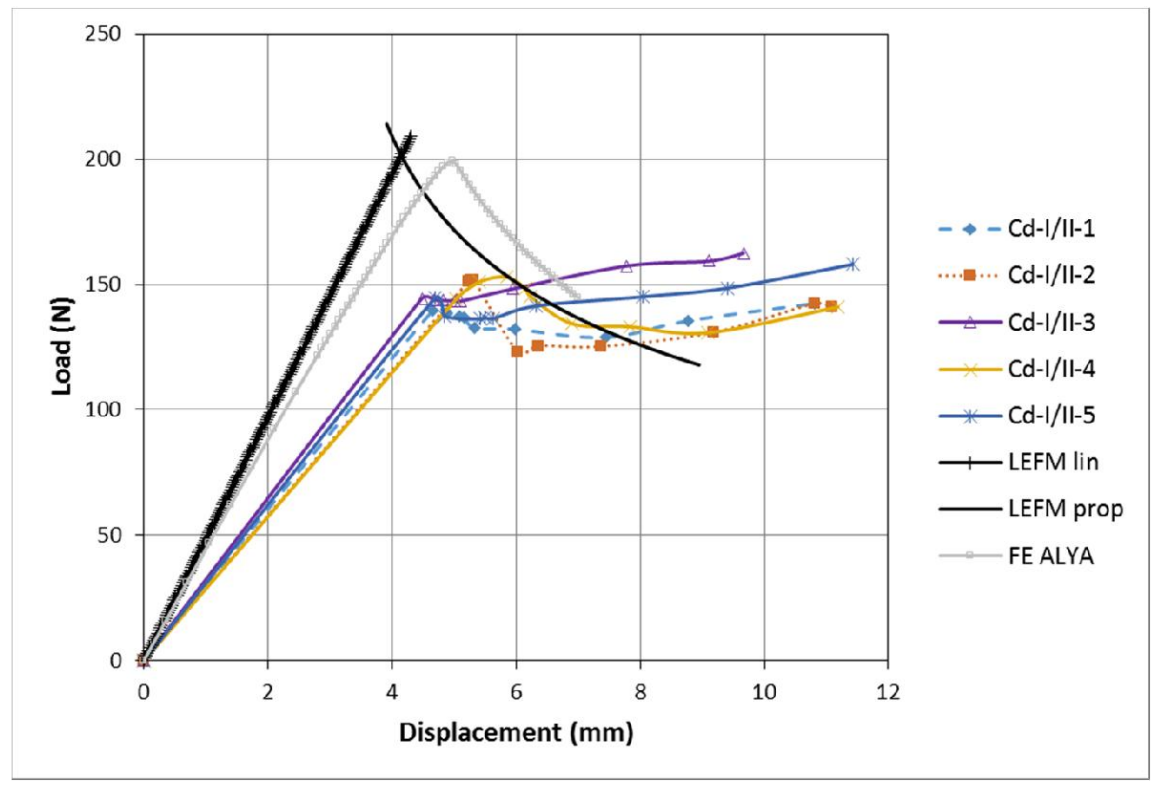

(a)

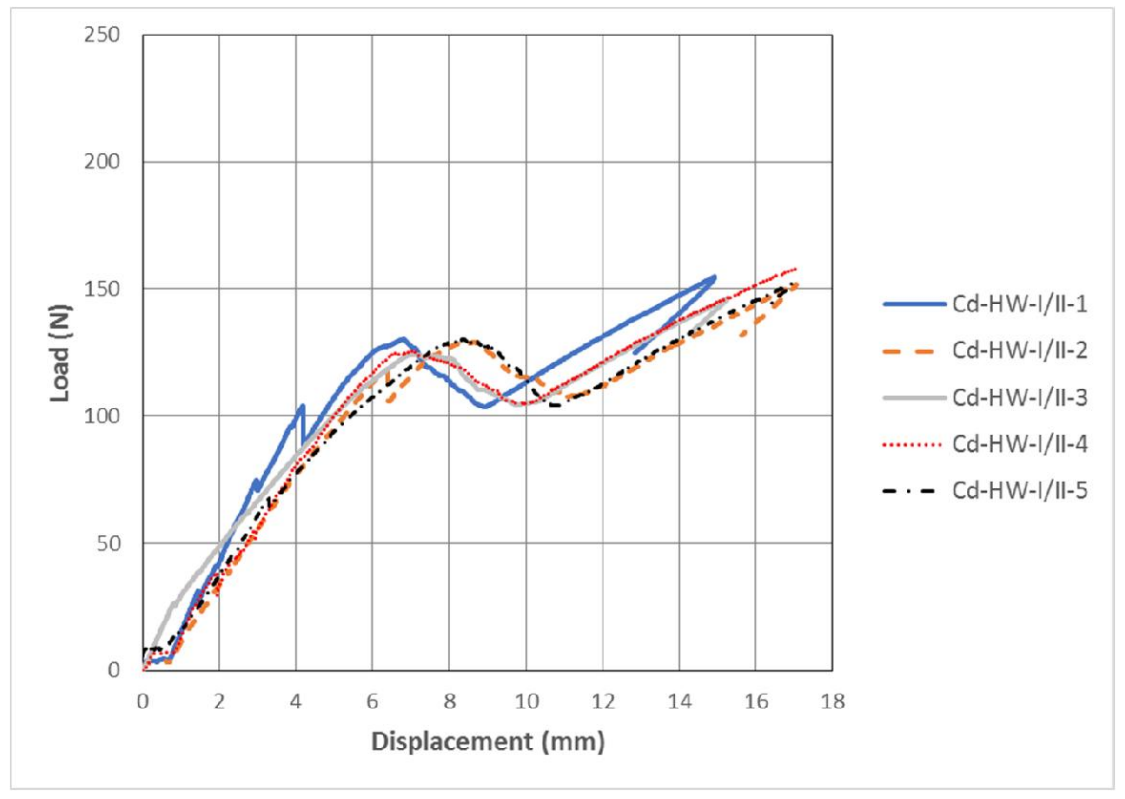

(b)

Figure 17: Transverse load vs opening displacement data during delamination propagation of CNT-doped laminate subjected to mixed Mode I/II fracture: (a) RT, (b) HW.

Characteristic values extracted from load-displacement curves of the two composite material systems in non-aged and aged state are presented in Table 10 and Table 11, 
respectively. These values are essential for calculating the mixed-mode fracture toughness presented later on. In both Tables the superiority of the CNT-doped material system in terms of maximum load and slope is explicitly quantified.

\begin{tabular}{|c|c|c|c|c|c|}
\hline System & specimen & $P_{\max }(\mathrm{N})$ & $\begin{array}{c}u_{\max }\left(\delta_{\max } \text { in }\right. \\
[16])(\mathrm{mm})\end{array}$ & slope $(\mathrm{N} / \mathrm{mm})$ & $R^{2}$ \\
\hline \multirow{5}{*}{$\bar{\Sigma}$} & $\mathrm{C}-\mathrm{I} / \mathrm{II}-1$ & 114.1 & 8.9 & 38.3 & 0.999 \\
\hline & C-I/II-2 & 145.6 & 8.8 & 52.9 & 1.000 \\
\hline & $\mathrm{C}-\mathrm{I} / \mathrm{II}-3$ & 142.3 & 7.4 & 48.0 & 1.000 \\
\hline & C-I/II-4 & 134.8 & 10.3 & 40.7 & 0.997 \\
\hline & C-I/II-5 & 132.8 & 11.0 & 35.9 & 0.997 \\
\hline \multirow{5}{*}{$\stackrel{\nabla}{\Sigma}$} & Cd-I/II-1 & 165.1 & 10.9 & 44.1 & 1.000 \\
\hline & Cd-I/II-2 & 153.1 & 11.1 & 37.5 & 1.000 \\
\hline & Cd-I/II-3 & 154.8 & 9.7 & 43.6 & 0.999 \\
\hline & Cd-I/II-4 & 154.4 & 11.2 & 32.4 & 0.999 \\
\hline & Cd-I/II-5 & 153.4 & 11.5 & 36.7 & 0.997 \\
\hline
\end{tabular}

Table 10: Experimentally determined parameters [16] for the two RT composite material systems in mixedmode I/II fracture test

\begin{tabular}{|c|c|c|c|c|c|}
\hline System & specimen & $P_{\max }(\mathrm{N})$ & $\begin{array}{c}u_{\max }\left(\delta_{\max } \text { in }\right. \\
[16])(\mathrm{mm})\end{array}$ & slope (N/mm) & $R^{2}$ \\
\hline \multirow{4}{*}{$\Sigma$} & C-I/II-1 & 97.4 & 11.7 & 21.7 & 0.999 \\
\hline & C-I/II-2 & 102.4 & 13.1 & 16.1 & 1.000 \\
\hline & C-I/II-3 & 105.4 & 11.5 & 24.1 & 1.000 \\
\hline & C-I/II-4 & 97.4 & 12.2 & 18.0 & 1.000 \\
\hline \multirow{5}{*}{$\stackrel{\nabla}{\Sigma}$} & Cd-I/II-1 & 161.9 & 15.9 & 32.9 & 1.000 \\
\hline & Cd-I/II-2 & 160.4 & 18.3 & 22.5 & 0.999 \\
\hline & Cd-I/II-3 & 155.6 & 16.2 & 17.6 & 0.999 \\
\hline & Cd-I/II-4 & 161.0 & 18.4 & 24.0 & 0.997 \\
\hline & Cd-I/II-5 & 153.1 & 18.0 & 24.3 & 1.000 \\
\hline
\end{tabular}

Table 11: Experimentally determined parameters [16] for the two HW composite material systems in mixed-mode I/II fracture test

Figure 18(a)-(b) highlights the effect of CNT-doping on the mixed-mode ILFT in terms of strain energy release rate $\left(G_{c}\right)$. For the determination of $G_{c}$ the measured flexural modulus of the control material (section 7.1) has been used. The nominal value of $G_{c}$ assessed by the MMB test is the one corresponding to propagation onset. This value usually corresponds to visual inspection of propagation onset and is actually low in the curve. Higher values of ILFT occur at later propagation stages. Clearly, CNT-doping leads to a drastic increase of mixed-mode fracture toughness of the base material throughout crack propagation, including higher slope and maximum value. 


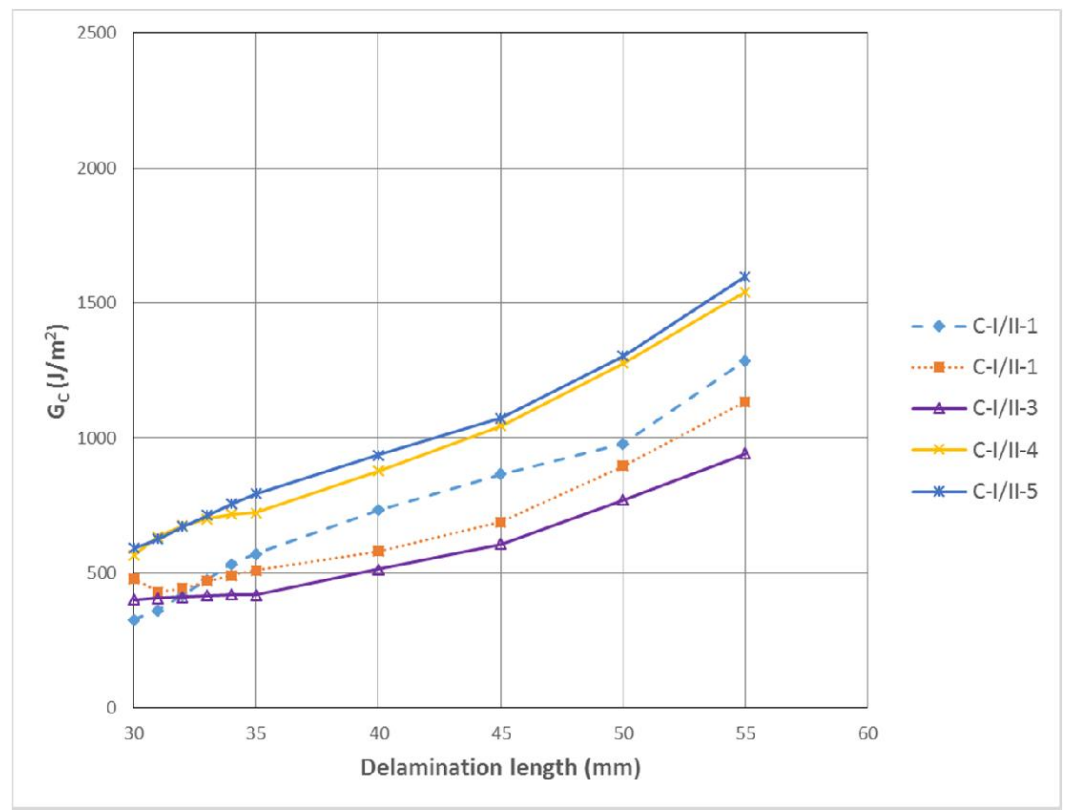

(a)

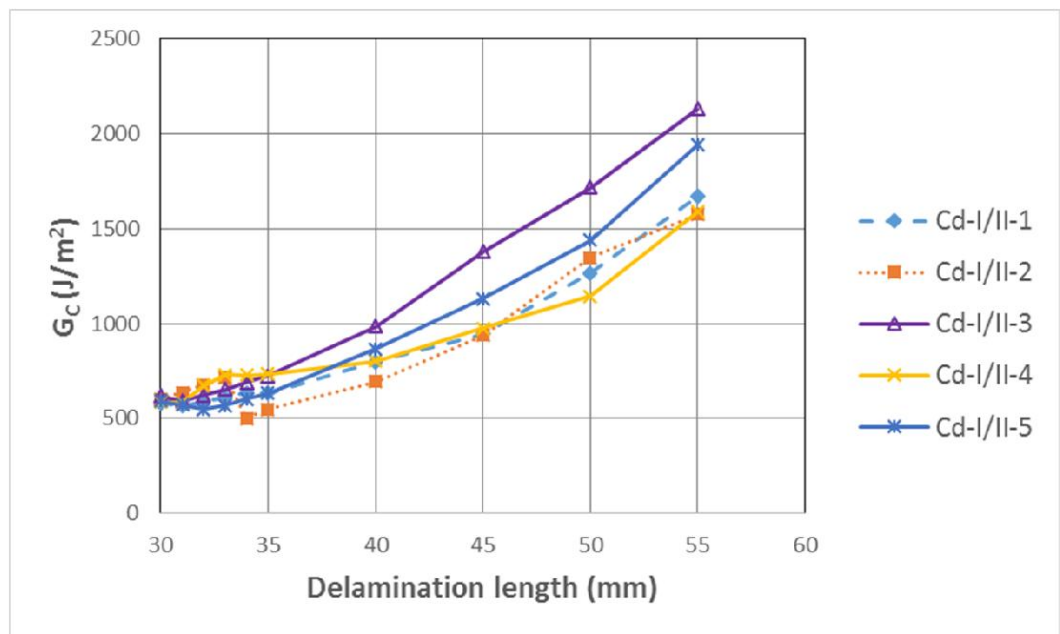

(b)

Figure 18: Strain energy release rate vs delamination length for RT material systems: (a) control laminate and (b) CNT-doped laminate specimens.

Similar conclusions may be drawn from Figure 19(a)-(b), where the effect of CNTdoping on aged material systems is presented. Besides drastic increase in mixedmode fracture toughness there is also an intermediate plateau before a steep ascent in the further propagation steps, which could be attributed to elastic energy accumulated in the upper part of the cracked specimen due to excessive bending, facilitated by increased ductility compared to the RT case. 


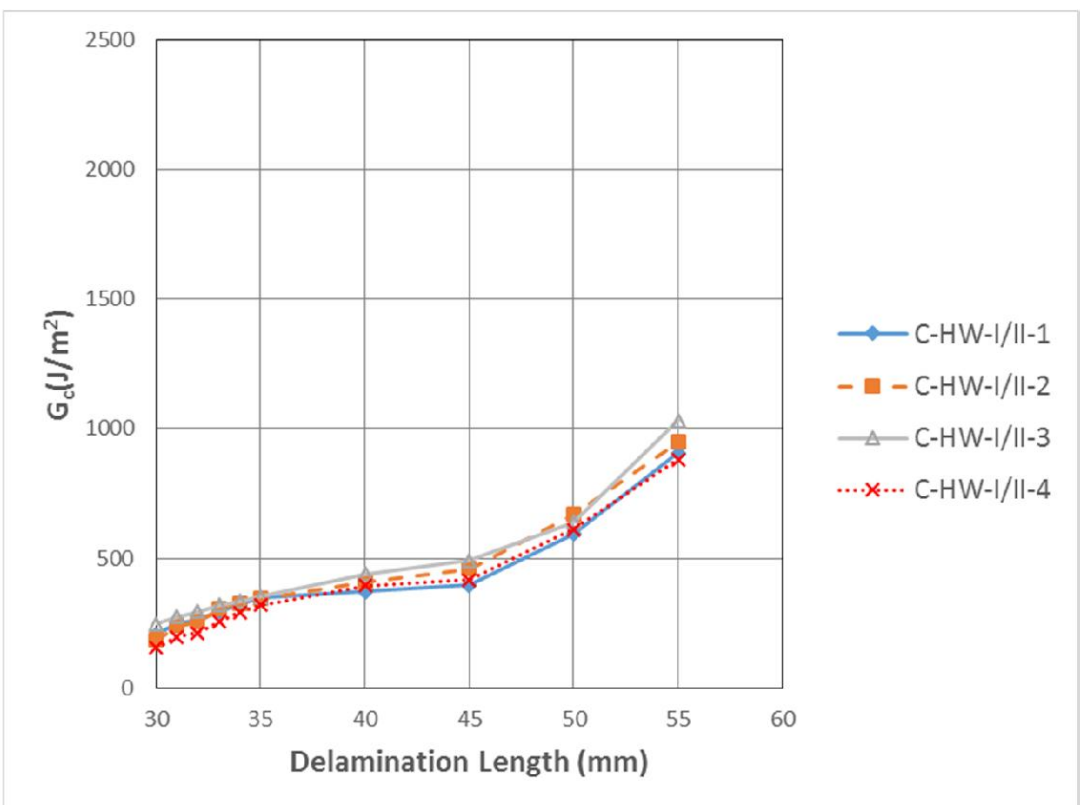

(a)

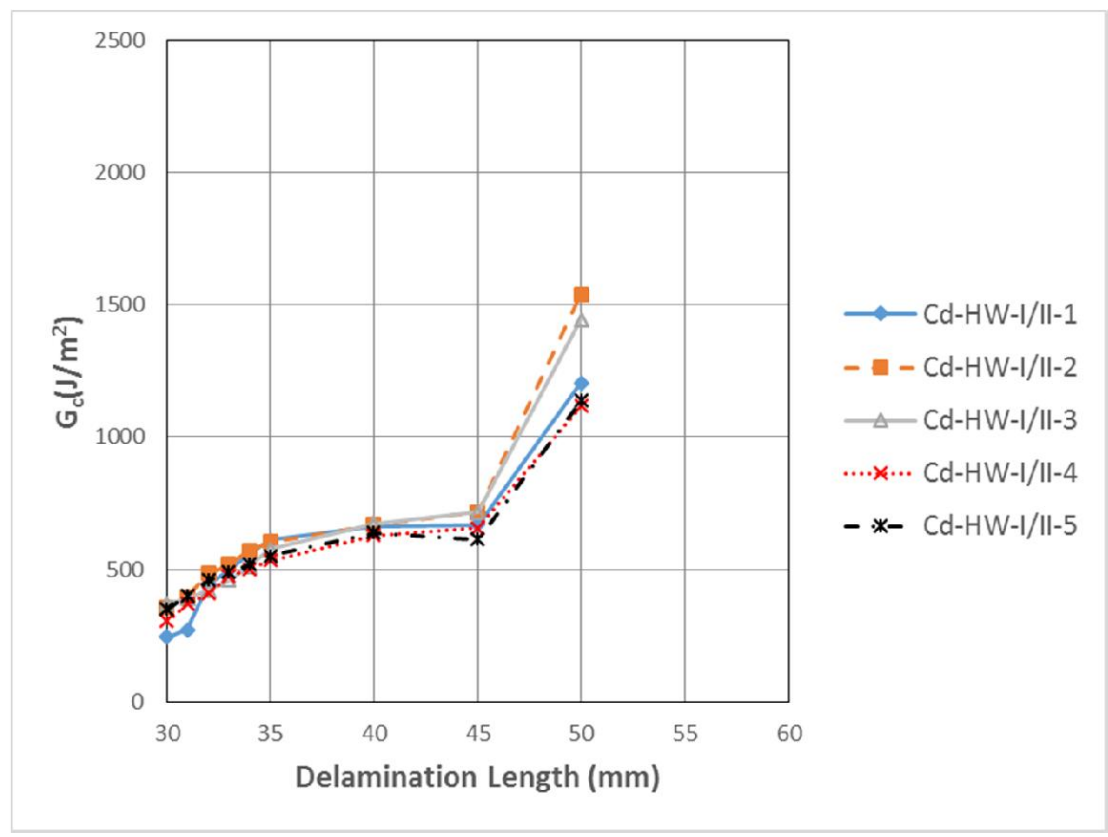

(b)

Figure 19: Strain energy release rate vs delamination length for HW material systems: (a) control laminate and (b) CNT-doped laminate specimens.

By comparing Figure 18 with Figure 19 it may be pointed out that aging leads to decrease of the MMB fracture toughness. That point has already been obvious from the load-displacement diagrams presented in Figure 15 and Figure 17, as well as, from the maximum load and slope values reported in Table 10 and Table 11. This trend may be attributed to slightly modified experimental set-up used for HW specimens compared to the one used for RT coupons. As reported in the MMB configuration description and illustrated in Figure 5(b), additional aluminum pads have been applied between hinge and specimen surfaces. These pads might affect the moments induced at the crack front, resulting in lower force application for crack propagation. 


\section{Summary and Conclusions}

The effects of aging and CNT-doping on interlaminar fracture toughness of a prepreg Graphite/Epoxy composite material system subjected to Modes I, II and I/II has been experimentally studied. Plates have been fabricated by hand lay-up and usual autoclave process, from which coupons have been cut. DCB, ENF and MMB tests have been performed in order to quantify these effects and provide measured data in batch mode. Intermediate calculated values have been reported in order to guide potential readers throughout the data evaluation process. In the case of non-aged coupons test data have been compared with outputs of analytical solutions and nonlinear finite element models developed in-house or in commercial software. The main conclusions arising from the present study are listed below:

- In all fracture modes studied the aged coupons yield more uniform behavior (lower variance) compared to the non-aged material systems. That trend may indicate that aging leads to plasticization of the matrix and thus to smoothening of material discontinuities caused by fabrication and/or loading.

- CNT-doping leads to an increase in fracture toughness in all modes studied, especially in shear-dominated Mode II where it reaches an approximate rise of $100 \%$.

- Aging leads to a fracture toughness drop in mixed Mode $\mathrm{I} / \mathrm{II}$ for control and CNT-doped laminates, whereas in Modes I and II the effect of aging on fracture toughness is rather minor.

- The CNT-doped laminate appears to be more sensitive to aging than the control laminate in the mixed Mode I/II.

- The MMB test appears to be the most sensitive to geometric and/or material imperfections, as indicated by the relatively large scattering in the measured load-displacement curves.

- Analytical/numerical predictions compare well with measured data in the case of Mode I and Mode II tests, whereas there is considerable deviation in the case of the MMB test. The latter may be attributed to overestimation of calculated strength values used in the models, as well as, to the fact that ILFT of pure Modes I and II may have to be elaborated in order to apply to prediction of the mixed-mode fracture toughness.

\section{Acknowledgement}

The current work has received funding from EU Horizon 2020 Clean Sky II project SHERLOC (Structural Health Monitoring, Manufacturing and Repair Technologies for Life Management of Composite Fuselage) under Grant Agreement No CS2-AIR-GAM2014-2015-01. The authors from HAl would like to thank our ex-colleagues Dimitrios Habas and Stavros Kalogeropoulos for their major assistance with coupons fabrication and experimental work, respectively.

\section{References}

1. Aerospace composites market - Global industry analysis, size, share, growth, trends and forecast 2016-2024, https://www.transparencymarketresearch.com/pressrelease/aerospace-compositesmarket.htm; 2018 [accessed 14/1/2019]. 
2. Tang $\mathrm{Y}, \mathrm{Ye} \mathrm{L}$, Zhang Z, Friedrich $\mathrm{K}$. Interlaminar fracture toughness and CAI strength of fibre-reinforced composites with nanoparticles - A review. Composites Science and Technology 2013; 86.

https://doi.org/10.1016/j.compscitech.2013.06.021

3. Domun N, Hadavinia H, Zhang T, Sainsbury T, Liaghat GH, Vahid S. Improving the fracture toughness and the strength of epoxy using nanomaterials - a review of the current status. Nanoscale 2015; 7. doi:10.1039/C5NR01354B

4. Whitney JM, Browning CE, Hoogsteden W. A double cantilever beam test for characterizing Mode I delamination of composite materials. Journal of Reinforced Plastics and Composites 1982; 1(4).https://doi.org/10.1177/073168448200100402

5. Hashemi S, Kinloch AJ, Williams JG. Mechanics and mechanisms of delamination in a poly(ether sulphone)-fibre composite. Composites Science and Technology 1990; 37(4). https://doi.org/10.1016/0266-3538(90)90013-U

6. Carlsson LA, Gillespie JW, Pipes RB. On the analysis and design of the end-notched flexure (ENF) specimen for Mode II testing. Journal of Composite Materials 1986; 20(6). https://doi.org/10.1177/002199838602000606

7. Reeder JR, Crews JR. Mixed-mode bending method for delamination testing. AIAA Journal 1990; 28(7). https://doi.org/10.2514/3.25204

8. Kinloch AJ, Wang Y, Williams JG, Yayla P. The mixed-mode delamination of fibre composite materials. Composites Science and Technology 1993; 47(3). https://doi.org/10.1016/0266-3538(93)90031-B

9. Brunner AJ, Blackman BRK, Davies P. Mode I Delamination. In: Moore DR, Pavan A, Williams JG, editors. Fracture Mechanics Testing Methods for Polymers Adhesives and Composites, Oxford: Elsevier Science Ltd; 2001, p. 277-305.

10. Davies P, Blackman BRK, Brunner AJ. Mode II Delamination. In: Moore DR, Pavan A, Williams JG, editors. Fracture Mechanics Testing Methods for Polymers Adhesives and Composites, Oxford: Elsevier Science Ltd; 2001, p. 307-333.

11. Blackman BRK, Brunner AJ, Davies P. Delamination fracture of continuous fibre composites: Mixed-mode fracture. In: Moore DR, Pavan A, Williams JG, editors. Fracture Mechanics Testing Methods for Polymers Adhesives and Composites, Oxford: Elsevier Science Ltd; 2001, p. 335-359.

12. Blackman BRK, Brunner AJ, Williams JG. Mode II fracture testing of composites: a new look at an old problem. Engineering Fracture Mechanics 2006; 73(16). https://doi.org/10.1016/i.engfracmech.2006.05.022

13. ISO-15024. Fibre-reinforced plastic composites - determination of Mode I interlaminar fracture toughness, $\mathrm{G}_{\mathrm{lc}}$, for unidirectionally reinforced materials. ISO; 2001.

14. ASTM-D5528. Standard test method for Mode-I interlaminar fracture toughness of unidirectional fiber-reinforced polymer matrix composites. ASTM; 2001.

15. ASTM-D7905/D7905M. Standard test method for determination of the Mode II interlaminar fracture toughness of unidirectional fiber-reinforced polymer matrix composites. ASTM; 2014.

16. ASTM-D6671/D6671M. Standard test method for mixed Mode I-Mode II interlaminar fracture toughness of unidirectional fiber reinforced polymer matrix composites. ASTM; 2013.

17. Tay TE. Characterization and analysis of delamination fracture in composites: An overview of developments from 1990 to 2001. Applied Mechanics Reviews 2003; 56(1). doi:10.1115/1.1504848

18. Camanho PP, Davila CG, De Moura MF. Numerical simulation of mixed-mode progressive delamination in composite materials. Journal of Composite Materials 2003; 37(16). https://doi.org/10.1177/0021998303034505 
19. Chrysochoidis NA Saravanos DA. Generalized layerwise mechanics for the static and modal response of delaminated composite beams with active piezoelectric sensors. International Journal of Solids and Structures 2007; 44(25-26). https://doi.org/10.1016/j.ijsolstr.2007.07.004

20. Sorensen BF, Jacobsen TK. Characterizing delamination of fibre composites by mixed mode cohesive laws. Composites Science and Technology 2009; 69(3-4). https://doi.org/10.1016/i.compscitech.2008.11.025

21. Naghipour P, Schneider J, Bartsch M, Hausmann J, Voggenreiter H. Fracture simulation of CFRP laminates in mixed mode bending. Engineering Fracture Mechanics 2009; 76(18). https://doi.org/10.1016/j.engfracmech.2009.05.009

22. Turon A, Camanho P, Costa J, Dávila, C.G. A damage model for the simulation of delamination in advanced composites under variable-mode loading. Mechanics of Materials 2006; 38(11). https://doi.org/10.1016/j.mechmat.2005.10.003

23. Turon A, Camanho P, Costa J, Renart J. Accurate simulation of delamination growth under mixed-mode loading using cohesive elements: definition of interlaminar strengths and elastic stiffness. Composite Structures 2010; 92(8). https://doi.org/10.1016/j.compstruct.2010.01.012

24. Goutianos S, Sorensen BF. Path dependence of truss-like mixed-mode cohesive $\begin{array}{llll}\text { laws. } \quad \text { Engineering } \quad \text { Fracture } & \text { Mechanics }\end{array}$ https://doi.org/10.1016/i.engfracmech.2012.02.011

25. Orifici AC, Herszberg I, Thomson RS. Review of methodologies for composite material modelling incorporating failure. Composite Structures 2008; 86(1-3). https://doi.org/10.1016/j.compstruct.2008.03.007

26. Mishnaevski L, Brondsted P. Micromechanical modeling of damage and fracture of unidirectional fiber reinforced composites: A review. Computational Materials Science 2009; 44(4). https://doi.org/10.1016/j.commatsci.2008.09.004

27. Camanho P, Hallett $S$, editors. Numerical modelling of failure in advanced composite materials. $1^{\text {st }}$ ed. Woodhead Publishing; 2015.

28. Beaumont PWR, Soutis C, editors. The structural integrity of carbon fiber composites. Switzerland: Springer; 2017.

29. De Moura MFSF, Goncalves JPM, Silva FGA. A new energy-based mixed-mode cohesive zone model. International Journal of Solids and Structures 2016; 102-103. https://doi.org/10.1016/j.jijsolstr.2016.10.012

30. Turon A, Gonzalez EV, Sarrado C, Guillamet G, Maimi P. Accurate simulation of delamination under mixed-mode loading using a cohesive model with a modedependent penalty stiffness. Composite Structures 2018; 184. https://doi.org/10.1016/j.compstruct.2017.10.017

31. Gojny FH, Wichmann MHG, Köpke U, Fiedler B, Schulte K. Carbon nanotubereinforced epoxy-composites: enhanced stiffness and fracture toughness at low nanotube content. Composites Science and Technology 2004; 64(15). https://doi.org/10.1016/j.compscitech.2004.04.002

32. Tsantzalis S, Karapappas P, Vavouliotis A, Tsotra P, Kostopoulos V, Tanimoto T, Friedrich $\mathrm{K}$. On the improvement of toughness of CFRPs with resin doped with CNF and PZT particles. Composites: Part A 2007; 38(4). https://doi.org/10.1016/i.compositesa.2006.04.016

33. Karapappas P, Vavouliotis A, Tsotra P, Kostopoulos V, Paipetis A. Enhanced fracture properties of carbon reinforced composites by the addition of multi-wall carbon nanotubes. Journal of Composite Materials 2009; 43(9). https://doi.org/10.1177/0021998308097735 
34. Gates TS, Odegard GM, Frankland SJV, Clancy TC. Computational materials: Multi-scale modeling and simulation of nanostructured materials. Composites Science and Technology 2005; 65(15-16). https://doi.org/10.1016/j.compscitech.2005.06.009 35. Hammerand DC, Seidel GD, Lagoudas DC. Computational micromechanics of clustering and interphase effects in carbon nanotube composites. Mechanics of $\begin{array}{llll}\text { Advanced Materials and } & \text { Structures }\end{array}$ https://doi.org/10.1080/15376490600817370

36. Theodosiou TC, Saravanos DA. Numerical investigation of mechanisms affecting the piezoresistive properties of CNT-doped polymers using multi-scale models.

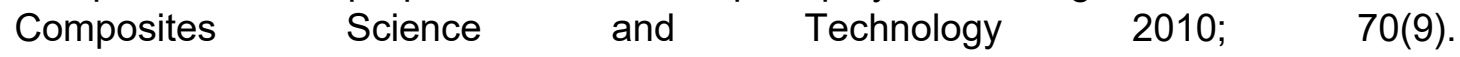
https://doi.org/10.1016/i.compscitech.2010.04.003

37. Thakre PR, Lagoudas DC, Riddick JC, Gates TS, Frankland SJV, Ratcliffe JG, Zhu $\mathrm{JJ}$, Barrera EV. Investigation of the effect of single wall carbon nanotubes on interlaminar fracture toughness of woven carbon fiber-epoxy composites. Journal of Composite Materials 2011; 45(10). DOI: 10.1177/0021998310389088

38. Wicks SS, Kalamoun S, Williams MR, De Villoria RG, Wardle BL. Effect of manufacturing route on Mode I fracture toughness of aligned carbon nanotube reinforced composites. AIAA conference paper 1567; 2012. https://doi.org/10.2514/6.2012-1567

39. Falzon BG, Hawkins SC, Huynh CP, Radjef R, Brown C. An investigation of Mode I and Mode II fracture toughness enhancement using aligned carbon nanotubes forests at the crack interface. Composite Structures 2013; 106. https://doi.org/10.1016/j.compstruct.2013.05.051

40. Ayatollahi MR, Shadlou S, Shokrieh MM. Mixed mode brittle fracture in epoxy/multi-walled carbon nanotube nanocomposites. Engineering Fracture Mechanics 2011; 78(14). https://doi.org/10.1016/j.engfracmech.2011.06.021

41. Silva H, Ferreira JAM, Capela $C$, Richardson MOW. Mixed mode interlayer fracture of glass fiber/nano-enhanced epoxy composites. Composites: Part A 2014; 64. https://doi.org/10.1016/j.compositesa.2014.05.011

42. Kumar A, Roy S. Characterization of mixed mode fracture properties of nanographene reinforced epoxy and Mode I delamination of its carbon fiber composite. Composites Part B 2018; 134. https://doi.org/10.1016/i.compositesb.2017.09.052

43. Abidin MSZ, Herceg T, Greenhalgh ES, Schaffer M, Bismarck A. Enhanced fracture toughness of hierarchical carbon nanotube reinforced carbon fibre epoxy composites with engineered matrix microstructure. Composites Science and Technology 2019; 170. https://doi.org/10.1016/j.compscitech.2018.11.017

44. Dikshit V, Bhudolia SK, Joshi SC. Multiscale polymer composites: a review of the interlaminar fracture toughness improvement. Fibers 2017; 5(38). doi:10.3390/fib5040038

45. Rodriguez-Gonzalez JA, Rubio-Gonzalez C. Influence of sprayed multi-walled carbon nanotubes on Mode I and Mode II interlaminar fracture toughness of carbon fiber/epoxy composites. Advanced Composite Materials 2018. https://doi.org/10.1080/09243046.2018.1458510

46. Rodriguez-Gonzalez JA, Rubio-Gonzalez C. Mixed-mode I/II interlaminar fracture toughness of carbon fiber/epoxy composites with the addition of multiwalled carbon nanotubes by spraying technique. Journal of Composite Materials 2018; 52(22). DOI: 10.1177/0021998318760383

47. Khan S, Bedi HS, Agnihotri PK. Augmenting Mode-Il fracture toughness of carbon fiber/epoxy composites through carbon nanotube grafting. Engineering Fracture Mechanics 2018; 204. https://doi.org/10.1016/i.engfracmech.2018.10.014 
48. Ravindran AR, Ladani RB, Wang CH, Mouritz AP. Synergistic Mode Il delamination toughening of composites using multi-scale carbon-based reinforcements. Composites Part A 2019; 117. DOI:10.1016/j.compositesa.2018.11.011

49. Garg A, Ishai $O$. Hygrothermal influence on delamination behavior of graphite/epoxy laminates. Engineering Fracture Mechanics 1985; 22(3). https://doi.org/10.1016/0013-7944(85)90142-0

50 . Selzer R, Friedrich K. Influence of water up-take on interlaminar fracture properties of carbon fibre-reinforced polymer composites. Journal of Materials Science 1995; 30(2). https://doi.org/10.1007/BF00354392

51. Zhao S, Gaedke M. Moisture effects on mode II delamination behavior of carbon/epoxy composites. Advanced Composite Materials 1996; 5(4). https://doi.org/10.1163/156855196X00112

52. Bowles KJ, Madhukar M, Papadopoulos DS, Inghram L, McCorkle L. The effects of fiber surface modification and thermal aging on composite toughness and its measurement. Journal of Composite Materials 1997; 31(6). https://doi.org/10.1177/002199839703100602

53. Tsotsis TK, Lee SM. Long-term durability of carbon- and glass-epoxy composite materials in wet environments. Journal of Reinforced Plastics and Composites 1997; 16(17). https://doi.org/10.1177/073168449701601707

54. Asp LE. The effects of moisture and temperature on the interlaminar delamination toughness of a carbon/epoxy composite. Composites Science and Technology 1998; 58(6). https://doi.org/10.1016/S0266-3538(97)00222-4

55. Chou I. Effect of fiber orientation and moisture absorption on the interlaminar fracture toughness of CFRP laminates. Advanced Composite Materials 1998; 7(4). https://doi.org/10.1163/156855198X00264

56. Chamis CC. Simplified composite micromechanics equations for strength, fracture toughness, impact resistance and environmental effects. NASA Technical Memorandum 836961984.

57. Davidson BD, Kumar M, Soffa MA. Influence of mode ratio and hygrothermal condition on the delamination toughness of a thermoplastic particulate interlayered carbon/epoxy composite. Composites Part A 2009; 40(1). https://doi.org/10.1016/i.compositesa.2008.10.006

58. Alessi S, Pitarresi G, Spadaro G. Effect of hydrothermal ageing on the thermal and delamination fracture behaviour of CFRP composites. Composites Part B 2014; 67. https://doi.org/10.1016/j.compositesb.2014.06.006

59. Fard MY, Raji B, Woodward JM, Chattopadhyay A. The effects of in-service induced reduction of bonding quality on the mode I, II and I-II fracture toughness of CNT nanocomposites. Proceedings of the ASME 2016 IMECE. doi:10.1115/IMECE2016-66907

60. Rodriguez-Gonzalez JA, Rubio-Gonzalez C, Ku-Herrera JJ, Ramos-Galicia L, Velasco-Santos $C$. Effect of seawater ageing on interlaminar fracture toughness of carbon fiber/epoxy composites containing carbon nanofillers. Journal of Reinforced Plastics \& Composites 2018; 37(22). https://doi.org/10.1177/0731684418796305

61. Fard MY, Raji B, Woodward $\mathrm{J}$ and Chattopadhyay A. Characterization of interlaminar fracture modes I, II and I-II of carbon/epoxy composites including inservice related bonding quality conditions. Polymer Testing 2019; in press. https://doi.org/10.1016/i.polymertesting.2019.05.010

62. MSC Software, Marc Volume A: Theory and User Information (2012).

63. Casoni E, Jérusalem A, Samaniego C, Eguzkitza B, Lafortune P, Tjahjanto D.D, Sáez X, Houzeaux G, Vázquez M. Alya: Computational Solid Mechanics for 
Supercomputers. Archives of Computational Methods in Engineering 2015; 22(4). https://doi.org/10.1007/s11831-014-9126-8

64. Vodicka R. Accelerated environmental testing of composite materials. Australian Department of Defense 1998.

65. ASTM D5229/D5229M, "Standard Test Method for Moisture Absorption Properties and Equilibrium Conditioning of Polymer Matrix Composite Materials", ASTM; 2014.

66. Composite Materials Handbook $\mathrm{CMH}-17$ Rev G Polymer Matrix Composites, Volume 1-Guidelines, Chapter 2, USA Department of Defense, 2011.

67. ASTM-D3039/D3039M. Standard test method for tensile properties of polymer matrix composite materials. ASTM; 2014.

68. ASTM-D695. Standard test method for compressive properties of rigid plastics. ASTM; 2002.

69. UNE-EN 2850 - Aerospace series - Carbon fibre thermosetting resin Unidirectional laminates - Compression test parallel to fibre direction (Endorsed by Asociación Española de Normalización); 2017.

70. ASTM-D3518/3518M. Standard test method for in-plane shear response of polymer matrix composite materials by tensile test of a $\pm 45^{\circ}$ laminate. ASTM; 2013.

71. ASTM-D2344/D2344M. Standard test method for short-beam strength of polymer matrix composite materials and their laminates. ASTM; 2006.

72. ASTM-D7264/D7264M. Standard test method for flexural properties of polymer matrix composite materials. ASTM; 2007.

73. Blanco N, Turon A, Costa J. An exact solution for the determination of the mode mixture in the mixed-mode bending delamination test. Composites Science and Technology 2006; 66(10). https://doi.org/10.1016/i.compscitech.2005.10.028

74. Turon A, Davila CG, Camanho PP, Costa J. An engineering solution for mesh size effects in the simulation of delamination using cohesive zone models. Engineering Fracture Mechanics 2007; 74(10). https://doi.org/10.1016/i.engfracmech.2006.08.025 75. Benzeggagh ML, Kenane M. Measurement of mixed-mode delamination fracture toughness of unidirectional glass/epoxy composites with mixed-mode bending apparatus. Composites Science and Technology 1996; 56(4). https://doi.org/10.1016/0266-3538(96)00005-X

76. Brouzoulis J, Fagerström M, Främby J, Krollmann J, Hellström P. Modelling of propagating delaminations in textile reinforced duroplastic beams by an enriched shell element formulation. $20^{\text {th }}$ International Conference on Composite Materials, Copenhagen 2015. 